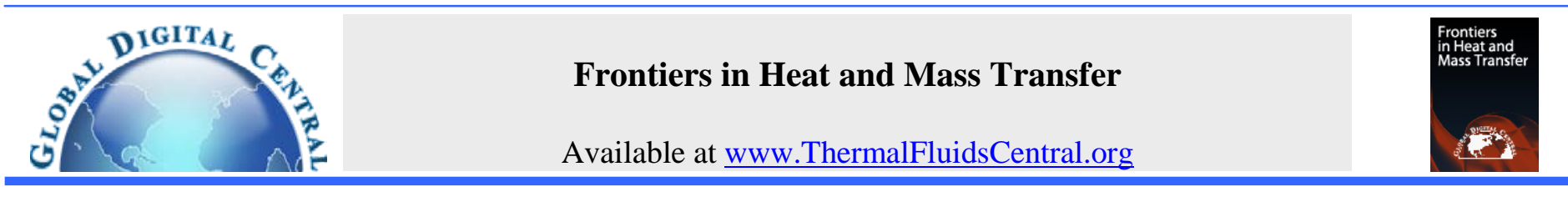

\title{
CRITICAL HEAT FLUX DURING FLOW BOILING IN MINI AND MICROCHANNEL-A STATE OF THE ART REVIEW
}

\author{
P. K. Das ${ }^{*}$, S. Chakraborty, S. Bhaduri \\ Department of Mechanical Engineering, Indian Institute of Technology Kharagpur, 721302, India
}

\begin{abstract}
A state of the art review of critical heat flux during flow boiling through mini and microchannels has been provided based on the open literature. This review mainly examines three aspects, namely the experimental investigations, the available correlations and the state of prediction using those correlations and finally the proposed physical mechanisms as well as the theoretical models. Before discussing the specific literature on microchannels, a brief overview of critical heat flux for pool and flow boiling is provided. The review has been concluded with a summary of the available information on this topic and the need for future research.

Keywords: Critical heat flux, minichannel and microchannel, sub cooled boiling, saturated boiling, mechanistic model
\end{abstract}

\section{INTRODUCTION}

Microchannel cooling holds an enormous potential for the further development of many cutting edge technologies like space systems, microelectronics, MEMS, photonics etc. Efficient thermal management of such systems not only increases the reliability and functionality but will also help to achieve the next level of miniaturization. In fact, the development of terahertz computers will only be possible through some unique breakthrough (Chung et al., 2011) in the existing cooling technology. One can definitely hope to see a greater deployment of microchannel cooling in miniature refrigeration plants, medical appliances, automobile heat exchangers etc. It is not surprising that there is a tremendous upsurge of interest in the field of microchannel flow and microchannel cooling in recent years. This itself has culminated in the development of diverse techniques for the fabrication of microchannels, methodology for driving flow through such conduits and efforts for understanding and characterizing this unique domain of fluid dynamics. The research initiative in this field can be appreciated not only from the expanding volume of publications on this topic but also from the launching of new journals and organization of many topical conferences.

As the development of various technology demands the dissipation of ever increasing thermal energy from the smallest possible volume, the thrust in microcooling technique has experienced a shift from the gas cooling to single phase liquid cooling and then naturally to cooling with a change of phase like boiling or evaporation (Agostini et al., 2007).

For any system, where heat is dissipated by boiling, the operation is restricted to the nucleate boiling regime to exploit the associated high heat transfer rate. Microchannels are no exception. Critical heat flux signifies the highest limit of the nucleate boiling heat transfer in any system; micro or macro. Beyond critical heat flux, there is not only a deterioration of the capability of heat dissipation, but also a potential risk of damage due to burn-out. The present article aims at a comprehensive review of the critical heat flux during flow boiling through microchannels based on published literature.

\section{DEFINITION OF MICROCHANNELS}

Before proceeding with the review, it would be prudent to define its scope by defining microchannels. Though the word microchannel may give the usual connotation for a channel with dimensions (or at least one dimension) of its cross-section of the order of a few microns ( $\simeq 10 \mu \mathrm{m}$, say); it is used rather loosely in practice. It has been argued elsewhere (Thome, 2007), that the distinctive features of two-phase flow in microchannel do not appear suddenly at a particular channel dimension. There is a gradual change of flow characteristics from macrochannel to microchannel over a range of physical dimensions as one can expect a typical flow regime to transform into another gradually due to the change in operating parameters.

Over the years, it has been observed that as the dimensions of the channel cross-section reduce, two phase flow starts exhibiting features different from those observed in large sized channels. The flow patterns and their transition boundaries in microchannels are distinguishingly different from those observed in macrochannels. Bhushan et al. (2009) demonstrated that the rise velocity of a Taylor Bubble will be strongly influenced by the orientation of the channel cross section when one of the dimensions is of the order of $\mathrm{mm}$. Almost three decades ago Barnea et. al. (1983) showed that gasliquid two-phase flow through horizontal tubes with diameters ranging from $4 \mathrm{~mm}$ to $12 \mathrm{~mm}$ has criteria for flow regime transition different from large sized tubes.

In essence, in case of two-phase flow, the effects of miniaturization can be envisaged much before the dimensions of the channel cross-section is reduced to micron level. Keeping this fact in mind, many researchers have tried to define a criterion for the transition from macro to microchannel. As the importance of surface force for gas-liquid two-phase flow through small-sized channels increases, Kew and Cornwell (1997) defined the Confinement Number Co, where,

$$
\begin{aligned}
& C o^{-2}=\text { Bo } \\
& \text { Bo }=\left(\rho_{1}-\rho_{\mathrm{V}}\right) g d^{2} / \sigma
\end{aligned}
$$

\footnotetext{
* Corresponding author: email: pkd@mech.iitkgp.ernet.in
} 
And microflow region is restricted by a boundary Co $>0.5$. More recently, Harirchian and Garimella (2009a, 2009b) have argued that the transition boundary between microflow and macroflow cannot be independent of the mass flux. They have defined the transition criteria as follows:

$B o^{0.5} \operatorname{Re}=\frac{1}{\mu}\left[\frac{g\left(\rho_{f}-\rho_{g}\right)}{2}\right] G d^{2}=160$

Nevertheless, the criterion for the transition from microflow to macroflow has not been universally established. For example, system pressure (Thome, 2007) can have a unique role in the bubble size and therefore on flow regime. Though the effect of pressure can be taken care of by considering the dependence of other fluid properties on it, a comprehensive study on the effect of pressure on the macro to micro transition is yet to be done. Under this scenario, the classification of microchannel flow and macrochannel flow and a probable mesochannel flow in between remains grossly ad hoc. In a recent review article, Revellin et. al. (2009) discussed the critical heat flux phenomena for situations where the Confinement number Co is much below 0.5. The present article is also not free from this ad hocism. We have tried to review the observations where the channel dimension (diameter, width or hydraulic diameter) is not greater than $3 \mathrm{~mm}$ in the absence of any universally accepted standards, in the title of the present article we have mentioned "mini and microchannels" to avoid any controversy.

\section{CHF IN POOL BOILING AND FLOW BOILING IN MACROCHANNELS - PRESENT STATE OF UNDERSTANDING}

Over the past half a century, CHF under various conditions like pool boiling, flow boiling through 'macro' channels and rod bundles over tube banks has been studied extensively. In spite of an overwhelming volume of literature on this topic; comprising of experimental data, mechanistic models and numerical simulations; understanding of CHF is only partial.

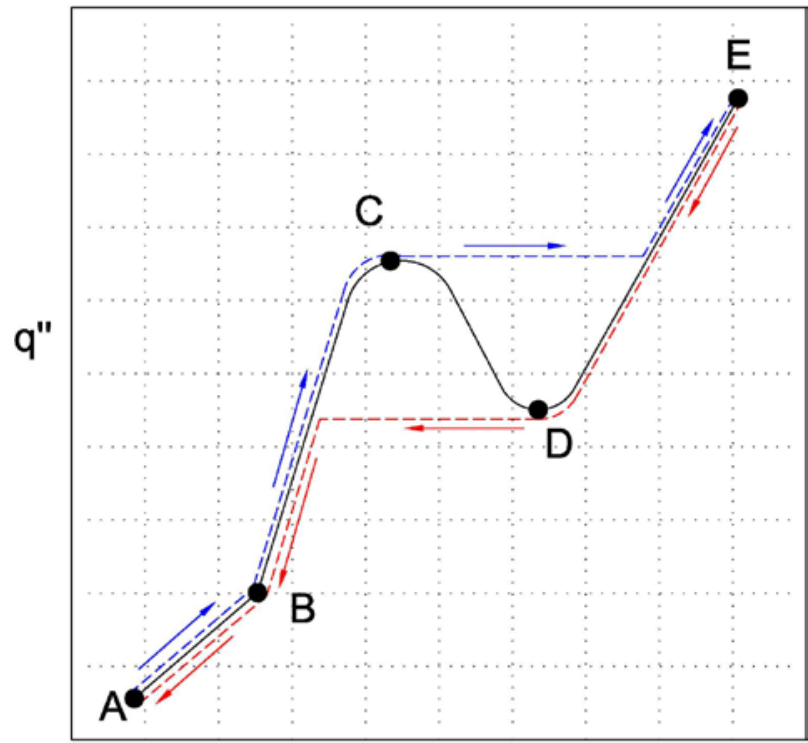

Tw-Ts

Fig. 1 Pool boiling curve. (a) _— Temperature controlled experiments, (b) heat flux controlled experiment, - - - - during heating, - - - - during cooling

The most fundamental studies on boiling heat transfer dates back to the work of Nukiyama (1966). Back in 1934, he demonstrated three distinct regimes in pool boiling through an innovative experimental scheme. The regimes of nucleate boiling, transition boiling and film boiling (Figure 1) were obtained by increasing the surface temperature of a temperature controlled heater. As shown in figure 1, the heat flux increases rapidly in the nucleate boiling regime (B to $\mathrm{C}$ ) till the critical heat flux (C) is reached. Beyond that, transition boiling (C to D), characterized by the partial blanketing of the heater surface by vapor patches, occurs and heat flux decreases with the increase of temperature.

This is not only an unstable region of boiling but also has to be avoided in most of the industrial applications. In the film boiling region ( $\mathrm{D}$ to $\mathrm{E}$ ) increasing heat flux is also associated with an increase in temperature, but this is not a preferred region of operation as the high temperature may induce the failure of the heater. On the other hand, if the heat flux of the heater is varied independently, there could be a sudden rise in temperature due to a small change in heat flux at the critical heat flux point (C). The boiling regime abruptly jumps from the nucleate boiling to the film boiling. This is again detrimental to the heater and is to be avoided at any cost. Therefore, the importance of critical heat flux and the necessity of its reliable prediction need not be over exaggerated. Though the above description has been made in the context of pool boiling, the same holds good for flow boiling except for some typical situations (Katto, 1994).

Critical heat flux is an outcome of a complex interplay of fluid dynamics, thermodynamics and heat transfer. It is influenced by a large number of process and system variables and is not fully understood till date (Chang and Baek, 2003). It would therefore be prudent to have a brief overview of critical heat flux before discussing the issue in connection with micro-channel boiling.

For pool boiling, mainly three different mechanisms of CHF have been postulated. At high heat flux, the vapor generated on the heating surface leaves in the form of circular jets arranged in regular array over the surface. Zuber (1959) and later Lienhard and Dhir (1973) postulated that the hydrodynamic instability of these jets is responsible for critical heat flux as that can disturb the replenishment of liquid to the surface. Figure 2 depicts the scenario during $\mathrm{CHF}$ as postulated by the hydrodynamic instability theory and considered as one of prominent mechanisms of CHF (Katto, 1994).

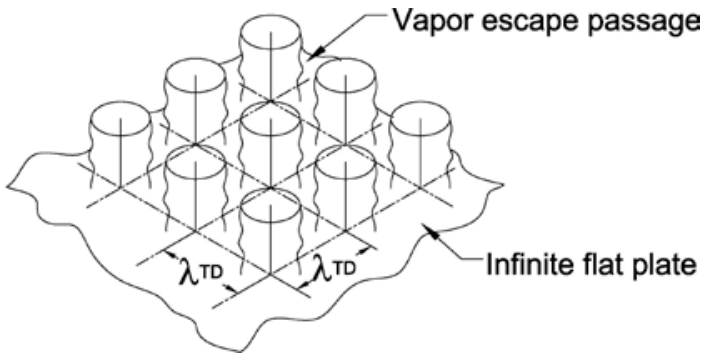

Fig. 2 Instability of vapor jets emerging from a flat horizontal surface

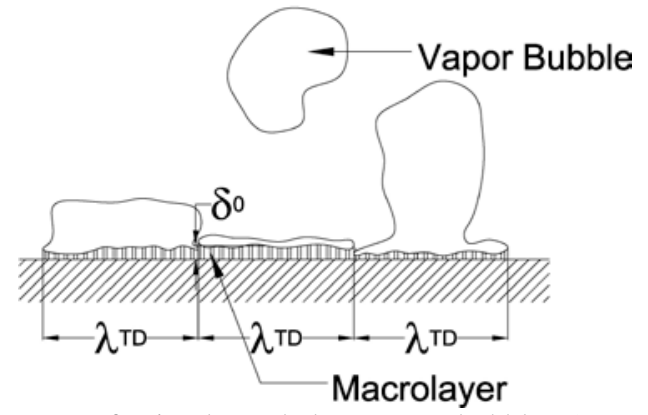

Fig. 3 Dryout of microlayer below vapor bubbles (Haramura and Katto, 1983) 
On the other hand Haramura and Katto (1983) drew the attention of the researchers to the near wall fluid behavior. They postulated that a growing bubble is fed by the vapor evaporated from a thin microlayer at its bottom and CHF occurs due to the dryout of the microlayer (Figure 3). It may be noted that the model is also applicable for flow boiling and for various configurations. It is also interesting to note that though the basis of the above two models are different; both of them predict similar parametric variation of CHF.

Dhir and Liaw (1989) proposed the existence of a thermal boundary layer adjacent to the heater surface during nucleate and transition boiling. It was further postulated that depending on the wettability and the temperature of the surface, the vapor stems undergo changes. Ultimately, the merging of the vapor stems triggers CHF. The idealized model as given by Liaw and Dhir (1989) and discussed by Katto (1994) is given in figure 4.

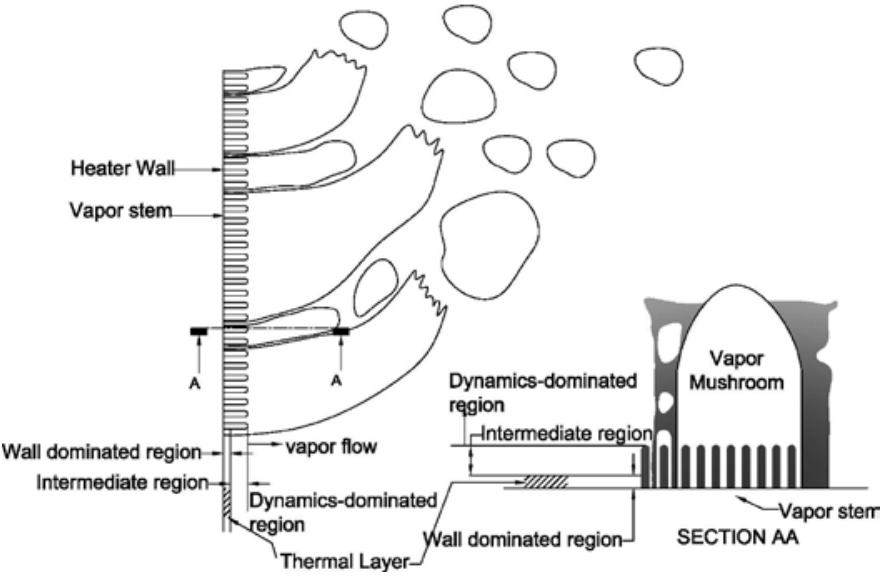

Fig. 4 Vapor stems connecting a bubble with the heater surface

Hydrodynamic instability and microlayer dry out appear to be the two main competitors as far as the mechanism of CHF is concerned. Bergles (1992) attempted a comparison of these two models. The effort for improvement on the basic models on CHF still continues. In this context, one may refer to the recent model of Kandlikar (2001a). In this model, the researcher included the effect of contact angle, surface orientation and subcooling.

There have also been attempts to pin-point the basic mechanism of CHF so that a single model can be applicable for pool and flow boiling. In this regard, importance has been given to the microlayer evaporation. The model of $\mathrm{Ha}$ and No $(1998,2000)$ may be mentioned. In the basic model, it is assumed that a dry spot is formed when there are a critical number of bubbles surrounding a single bubble. In this case, the liquid supply to the microlayer of the central bubble is restricted.

Critical heat flux in subcooled boiling is immensely important in industry for energy transfer and safety consideration. One cannot neglect the effect of bulk fluid movement and the lateral movement of the bubbles in modeling CHF in such situations. Kandlikar (2001b) provided a comprehensive review of the state of the understanding of CHF during subcooled flow boiling. He referred to the work of Celata and Mariani (1999) where the models based on the following mechanisms have been identified.

1. Boundary layer ejection model.

2. Critical enthalpy in bubble layer model

3. Liquid flow blockage model

4. Vapor removal limit and near wall bubble crowding model

5. Liquid sublayer dryout model

The readers may refer to Kandlikar (2001b) or Celata and Mariani (1999) to get an overview of the above mechanisms.

\begin{tabular}{|c|c|c|c|c|c|c|c|c|c|}
\hline 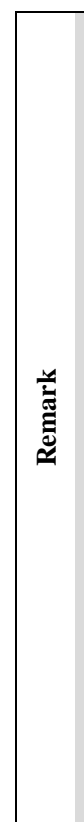 & 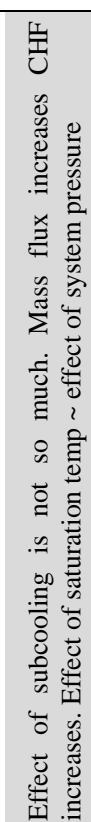 & 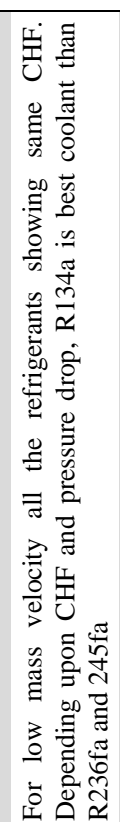 & 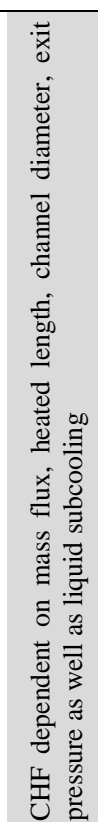 & 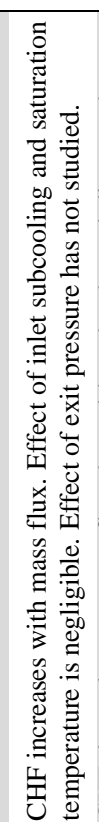 & 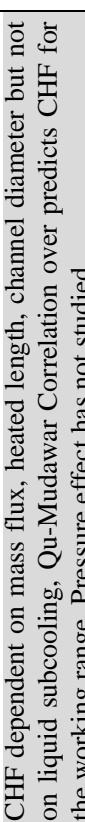 & 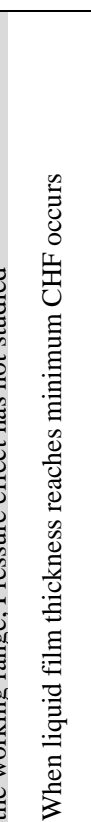 & 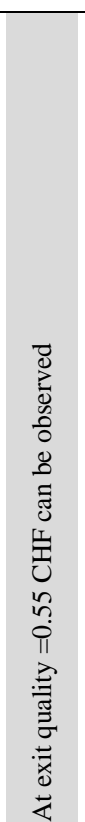 & 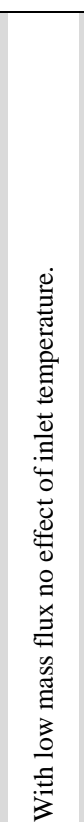 & 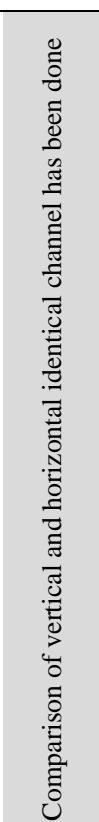 \\
\hline 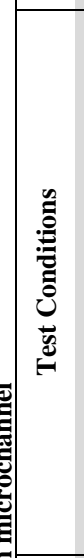 & 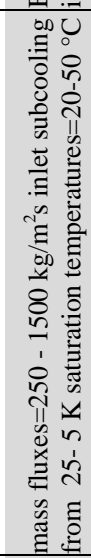 & 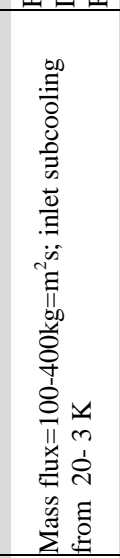 & 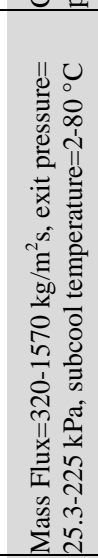 & 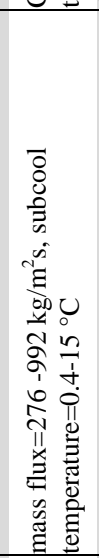 & 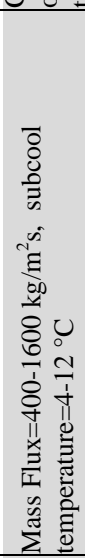 & 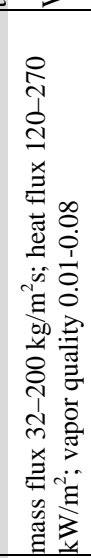 & 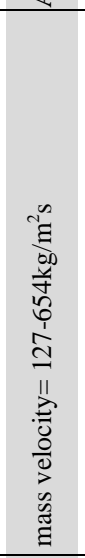 & 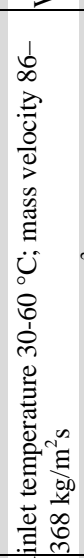 & 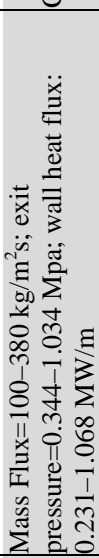 \\
\hline \multicolumn{3}{|c|}{ 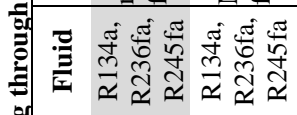 } & 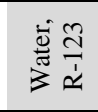 & 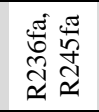 & 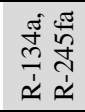 & 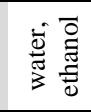 & $\begin{array}{l}\frac{\pi}{4} \\
\stackrel{m}{\pi} \\
\end{array}$ & 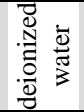 & $\begin{array}{l}\stackrel{ \pm}{\pi} \\
3\end{array}$ \\
\hline 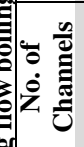 & ని & 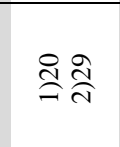 & $\begin{array}{l}\frac{o}{w 0} \\
: \bar{E}\end{array}$ & $\hat{\omega}$ & $\begin{array}{l}\frac{0}{00} \\
:=\end{array}$ & 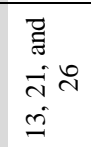 & กิ & $\vec{v}$ & $\begin{array}{l}\stackrel{0}{00} \\
\stackrel{\tilde{\omega}}{*}\end{array}$ \\
\hline Uूँ & 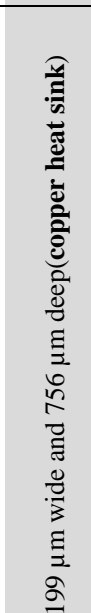 & 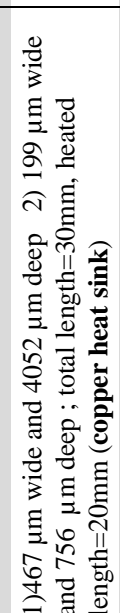 & 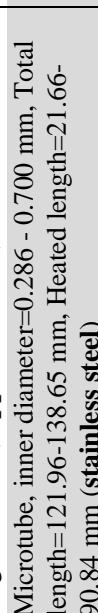 & 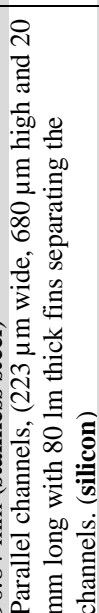 & 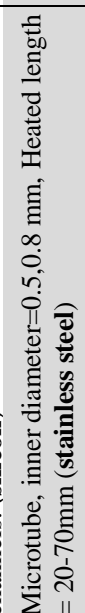 & 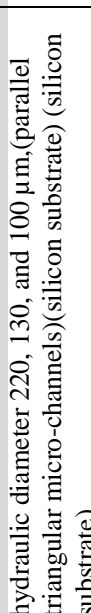 & 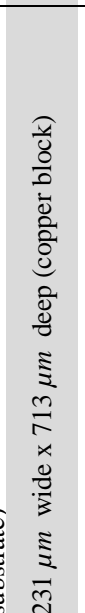 & 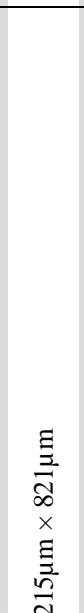 & 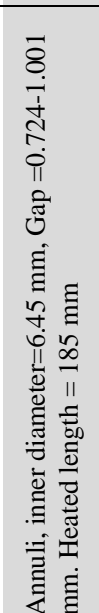 \\
\hline 咅 & 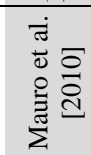 & 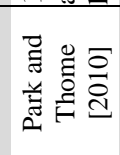 & 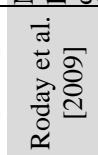 & 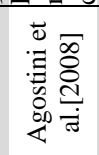 & 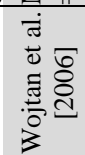 & 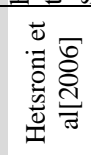 & 突 & 离 & 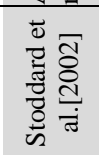 \\
\hline
\end{tabular}


It needs to be mentioned that none of the mechanisms can be considered for the modeling of CHF in microchannel flow boiling without substantial modifications. However, these models create the framework on which the probable mechanism of CHF in microchannels may be postulated. Particularly, thin film dryout could be a viable mechanism even in case of microchannel. But the dynamic situation during flow boiling cannot be ignored. The importance of the receding contact angle during evaporation in a moving fluid should be considered as a mechanistic representation.

\section{EXPERIMENTAL INVESTIGATIONS ON CHF}

Last decade has witnessed a very large number of experimental investigations on flow boiling through microchannels. Though experimental results have been obtained from different laboratories all over the globe, certain research groups are particularly very active. Some of these works are fundamental in nature while many of them are targeted to determine the performance of typical heat sinks relevant to the products of the sponsors. Though Bergles and Kandlikar (2005) reported the lack of information in single microchannel, a good number of experiments have also been conducted in such geometry or channel sizes in the milimetric and sub-milimetric range.

That the boiling behavior could be radically different in a narrow confinement was apprehended by a number of investigators (Kim et al., 2003; Bar-Cohen, 2008; Aoki et al., 1982; and Kim et al., 2004). The heat transfer coefficient, the flow regime and the critical heat flux changes depending on the geometry of the confinement, gap size and orientation of the heater surface (horizontal - up or down, inclined or vertical - up or down). Direct comparisons between the results are not possible due to the variation of orientation and geometry. However, all the investigations indicate a strong influence of flow regimes on CHF. Decrease of CHF due to counter current flow limitation (CCFL) was also observed. CCFL is reverse flow of the liquid phase as a result of vapor flow with a high velocity in a counter current direction. An analogue to this phenomenon is observed in microchannel. Reduction of CHF occurs as liquid flows in the reverse direction forced by the expanding vapor bubbles.

Experiments on microchannel cover a wide range of geometry, physical dimensions, working fluids and operating parameters. The expanse of the parametric range can be appreciated from the database provided in two earlier reviews (Ghiassiaan, 2001; Revellin and Thome, 2009). The readers are referred to these two sources as they complement the present topic. It may be noted that the two tables have only a marginal overlap. In the present work we provide some of the very recent and important experimental investigations in table 1 . The CHF data of the table also signifies the current direction of research.

Based on the available literature, one may note that experiments have been conducted in microtubes, and microchannels of rectangular cross section. In case of microtubes; both single (Roday and Jensen, 2007, 2009a, 2009b, Roday et al. 2008) and multiple tubes (Bower and Mudawar, 1994) have been used. On the other hand, a single microchannel has rarely been used for the study of CHF; data are available only from heat sink with parallel microchannels. Single microtubes are metallic while parallel channel heat sinks are made of both silicon and metal (copper and stainless steel).

Range of working fluids covers water, refrigerants (R134a, R245fa, R236fa, R123, R32, R113 etc.), $\mathrm{CO}_{2}$, nitrogen, helium, ethanol etc. Though the time is not right yet to propose the effect of fluid properties in definitive terms, CHF is significantly influenced by the type of fluid. Unless systematic experiments are planned to estimate CHF for different fluids using the same experimental facility, a comparison in true sense is not possible. Such studies are rare. Some studies in that direction could be identified from the work of Prof. J. R. Thome and co-workers (Mauro et al. 2010, Park and Thome, 2010). They have used R134a, R236fa, and R245fa in the same experimental set up and obtained a common trend of CHF for all the refrigerants. Nevertheless, the least value of CHF was recorded for R236fa and R134a could be recognized as the best cooling medium as far as pressure drop and CHF values are concerned. The investigators have also noted a negligible effect of saturation temperature on CHF within their range of experimental parameters.

Out of different geometrical parameters the hydraulic diameter and length to diameter ratio have a profound effect on CHF. For subcooled boiling, CHF increases with the decrease of channel diameter. This trend (figure 5 (a)) has consistently been observed by a number of researchers (Vandervort, 1994; Bergles, 1962). On the other hand for $x_{e q}>0$, CHF decreases with decrease in $d$. Bergles (1962) postulated that as the channel diameter decreases there is also a decrease in the departure diameter of the vapor bubbles. Further, bubble velocity relative to the liquid increases and condensation at the tip of bubble becomes stronger. The combined effect of these three facts is responsible for an increase in CHF with decrease in diameter. Almost all the investigations report a monotonic increase in CHF with the increase in mass flux. CHF also increases approximately linearly with the increase in subcooling as shown in figure 5(b) (Vandervort, 1994; Stoddard, 2002). However, the influence of subcooling is more pronounced at higher mass flow rate.

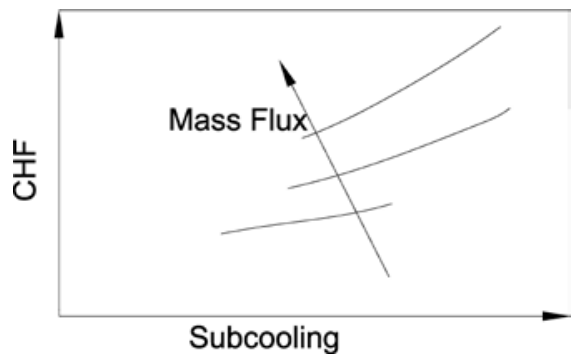

(a)

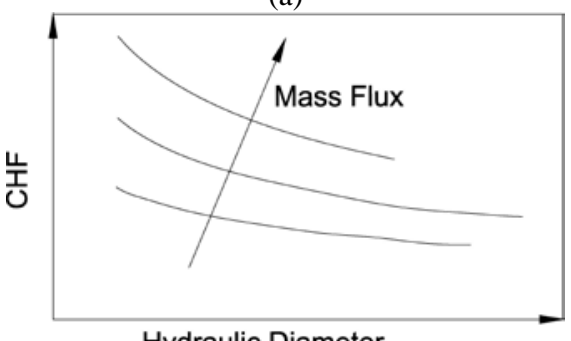

Hydraulic Diameter

(b)

Fig. 5 Variation of critical heat flux: (a) with hydraulic diameter, and (b) with inlet subcooling

\section{PREDICTION OF CHF THROUGH CORRELATIONS}

The earlier section discusses some important experimental investigations on flow boiling through microchannels. It has been observed that some trends of the variation of CHF have already emerged. This has encouraged the researchers to try for the prediction of CHF as a function of geometric and operational parameters as well as fluid properties. Such predictions can be made through correlations or modeling. In this section, the correlations for the CHF in microchannels have been examined while the effort for modeling $\mathrm{CHF}$ has been scrutinized in the next section.

In the endeavor of proposing correlations, often the researchers restrict themselves to limited data set generated from identical test conditions. This casts a doubt on the applicability of the correlation over a wider range. Fortunately, in case of microchannel boiling, a huge volume of data has been generated within a small period of time and some of the correlations have been developed using a large data set. One can identify three trends as far as the prediction of CHF in 
microchannel through correlations is concerned. Researchers tried to use correlations, already available for macro systems, modify some available correlations to comply with the experimental results of microchannels and to develop altogether new correlations. Table 2 provides a compilation of correlations relevant for the CHF in microchannel. It needs to be mentioned that this table is not meant to present an all-inclusive list. Nevertheless, it presents correlations very relevant for the present topic and those which has shown promise in predicting this complex phenomenon in microchannel.

In table 2, correlations have been listed chronologically, as they have been developed or proposed. For ease of ready cross-reference, some numbers enclosed in brackets have been inserted after some references within the main body of the text. These numbers correspond to the chronological serial numbers against the correlational equations as entered in Table.2.

In this table most of the correlations try to find out a logical relationship between $B l_{c h f}$ or $q_{c h f}$ and the operating, geometric and property variables. $B l_{c h f}$, the non-dimensional critical heat flux, is defined as $B l_{c h f}=q_{c h f} / G h_{l v}$. From the very definition it recognises a direct proportionality between the critical heat flux and the mass velocity. That the critical heat flux increases with the mass flow rate, has been an accepted fact in macro-systems and has also been established for microchannels beyond contradiction. Furthermore, from the basic physics, the CHF should be directly proportional to the enthalpy needed for vaporization. This trend also supports almost all the correlations and theories developed from diverse assumptions and approaches.

Four of the correlations of table 2, (Katto, 1978; Qu and Mudawar, 2004; Qi et al., 2007 and Wojtan et al. 2006) share similar structure and some common groups of non-dimensional numbers. In all these correlations, $q_{c h f}$ is proportional to a property group $\left(\rho_{l} / \rho_{V}\right)^{\alpha}$ where $\alpha>0$. The density difference between the phases indicates the ease with which the vapor can get separated from the liquid phase from an evaporating surface. On the other hand, this also signifies the location of the operating point with respect to the critical point and the magnitude of the enthalpy of vaporization. In general, the more the difference between the densities of saturated vapor and saturated liquid, higher will be the value of CHF. Further, CHF is proportional to $\left(1 / W e_{l o}\right)^{\beta}$ and $\left(L_{n} / d_{n}\right)^{-\gamma}$ where $\beta$ and $\gamma$ are positive entities. $W e_{l o}=G^{2} L / \sigma \rho$, the Weber number is the ratio of inertia to surface force. A dominance of surface force will enhance the CHF. Finally, for saturated flow boiling, an increase in D will increase the value of heat flux.

It may be noted that the first model due to Kato (1978)[1] was not developed specifically for microchannels. Rather it is very general, as CHF was assumed to depend on a large number of parameters

$$
B l_{c h f}=f\left(\frac{\rho_{l}}{\rho_{v}}, \frac{\mu_{l}}{\mu_{v}}, \frac{G^{2} L}{\sigma \rho}, \frac{\mu_{l}}{G L}, \frac{g\left(\rho_{l}-\rho_{v}\right)}{G^{2}}\right)
$$

Then the author has argued that the effect of viscosity is negligible in case of $\mathrm{CHF}$ and for forced convection, gravity plays a minor role. This reduces the above equation to

$$
B l_{c h f}=f\left(\frac{\rho_{l}}{\rho_{v}}, \frac{G^{2} L}{\sigma \rho}\right)
$$

Further, Katto assumes an idealised representation of boiling in a uniformly heated vertical tube as shown in figure 6 . For a limiting condition of $\mathrm{d} \rightarrow 0$, through vectorial dimensional analysis, he postulates

$$
B l_{\text {chf }} \frac{L}{d}=\text { const. }\left(\frac{\rho_{l}}{\rho_{v}}\right)^{a}\left(\frac{\sigma \rho}{G^{2} L}\right)
$$

This is the basis of the first correlation in table 2 .

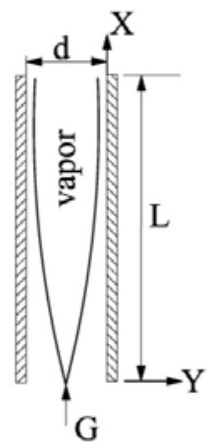

Fig. 6 Idealization of boiling in a uniformly heated vertical tube (Katto, 1978)

A few points may be noted regarding Katto's work. Firstly, the correlation was developed for uniformly heated vertical channels. In a vertical channel, stratification due to gravity is absent. In case of microchannels, even in horizontal orientation, the effect of gravity will not be prominent. Rather, the surface force will be important. Moreover, the above correlation was developed based on the assumption of a small $d$. Therefore, it is no wonder that the basic form of the correlation also satisfies the CHF variation in microchannels. Wu et al. (2011) used the Kato correlation for a large number of refrigerants, water and nitrogen, taking data from diverse sources and obtained a reasonable prediction.

The correlation by Katto and Ohno (1984) [2] has been used by a large number of researchers for predicting saturated CHF in a single channel. Originally, the correlation was developed for circular tubes and applied down to 3mm for normal refrigerants. Though the basic form of the correlation is similar to that of Katto (1978), it is capable of accounting for the subcooling with some modifications. Based on the assumption that CHF increases linearly with subcooling, the form of the equation (Table.2) was suggested. The correlation gives a reasonable prediction as indicated in the table.

It may be noted that compared to the correlations of CHF for vertical flow, the correlations for flow through horizontal channels, are scarce, especially at low mass fluxes. Groeneveld (1986) [3] has suggested a simple method of prediction for CHF in horizontal channel by multiplying the corresponding value in vertical tubes with a constant $k_{\text {hor }}$. According to Yu et al. (2002), this formula gives the correct trend of CHF in small tubes. When the CHF values obtained from the Groeneveld formula are plotted against mass quality, it is seen that CHF decreases with decreasing mass flux. This is opposite to what happens in macrotubes at large pressures and mass fluxes. Also, when compared to macrochannel data, the CHF qualities are high.

Next in line is the Shah correlation [4]. Shah (1987) has proposed a correlation for CHF in uniformly heated vertical channels from a database of 62 independent sources using 23 fluids (water, cryogens, organics and liquid metals) for channel diameters varying from $0.315 \mathrm{~mm}$ to $37.5 \mathrm{~mm}$ and heated length to diameter ratios from 1.2 to 940 . Shah's final correlation basically contains three piecewise defined sub-correlations, as determined by a parameter Y. Of these three correlations, the 'upstream conditions' correlation covers the situation where CHF at a location depends on the upstream conditions, e.g., inlet subcooling and distance from tube inlet. The 'local condition correlation' relates CHF to the local quality. 


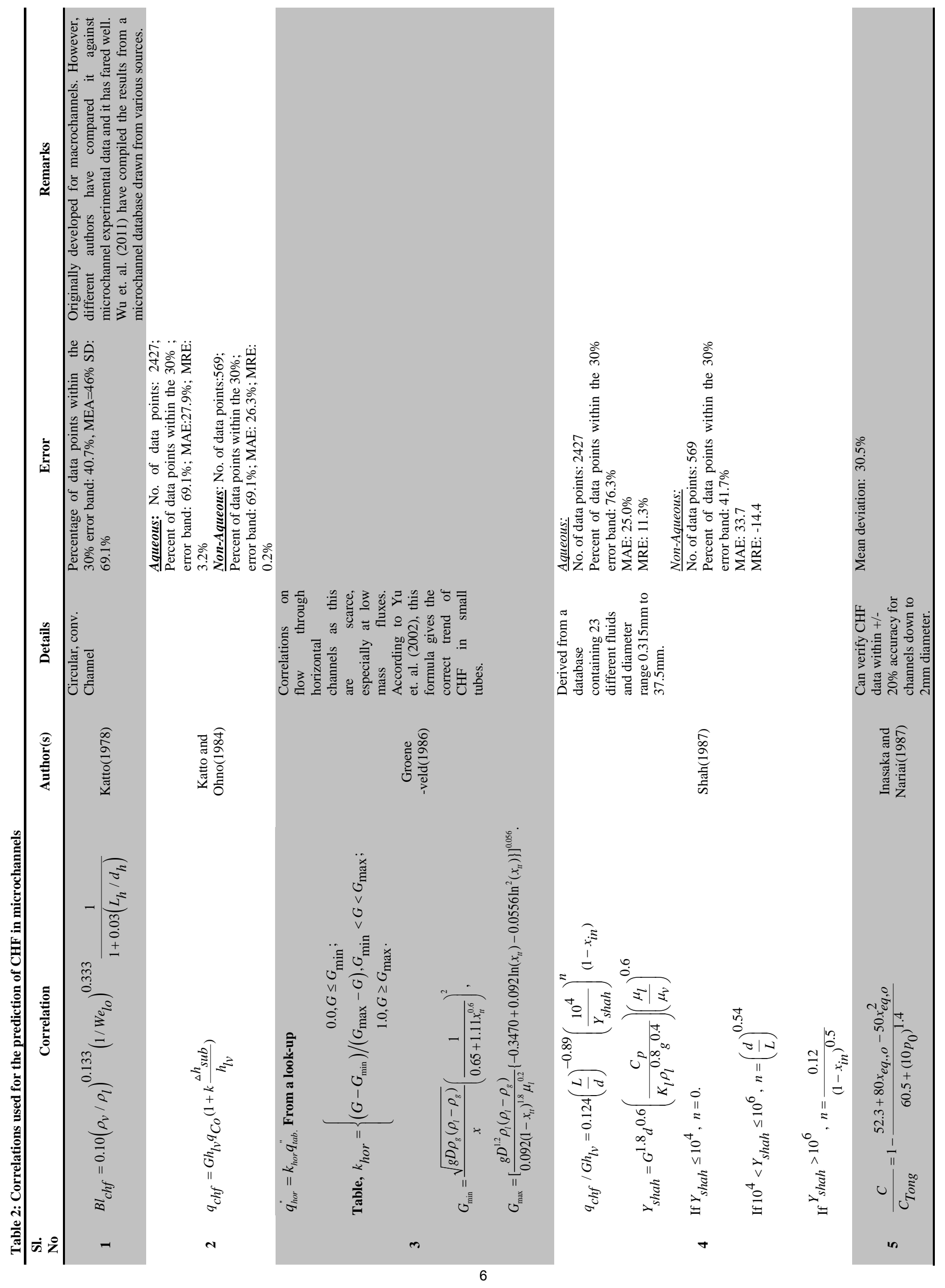




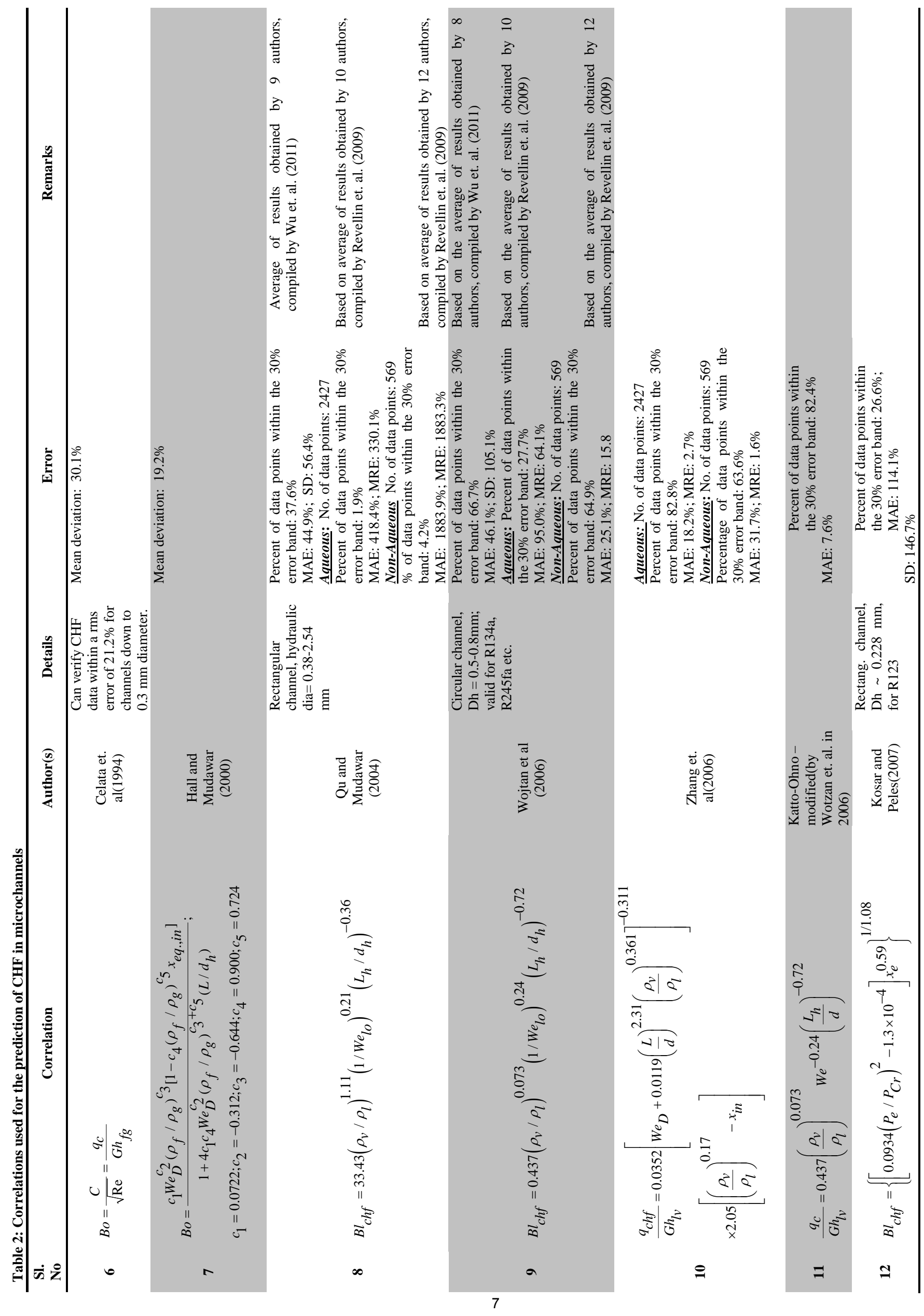




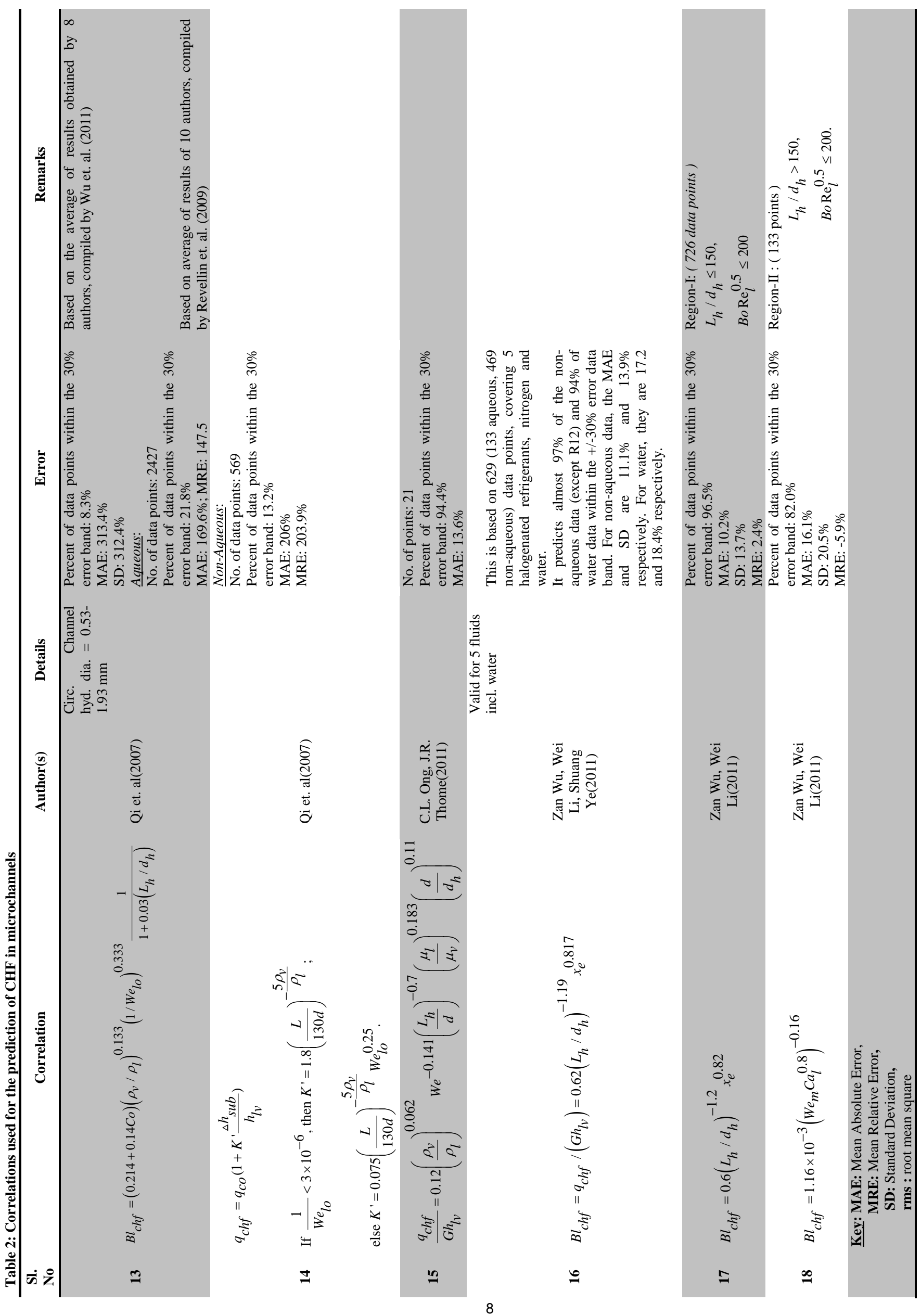


Tong (1968) derived a CHF correlation by applying boundary layer theory to the problem of a permeable plate with gas injection. His correlation contained a parameter $C_{\text {Tong }}$ which was given as a function of quality.

$$
\begin{aligned}
& q_{c}=C G \frac{h_{f g}}{\operatorname{Re}^{0.6}} \\
& C=1.70-7.43 x_{e q, o}+12.22 x_{e q, o}{ }^{2}
\end{aligned}
$$

Inasaka and Nariai (1987)[5] modified the parameter $C_{\text {Tong }}$ as follows:

$\frac{C}{C_{\text {Tong }}}=1-\frac{52.3+80 x_{\text {eq.,o }}-50 x_{\text {eq,o }}^{2}}{60.5+\left(10 p_{0}\right)^{1.4}}$

This modified equation has been successfully applied to channels of diameters down to $2 \mathrm{~mm}$.

Celata et al. (1994) [6] also modified Tong's correlation; both by modifying the parameter $\mathrm{C}$ as well as by changing the exponent of the Reynolds number. This correlation agreed well with the data for channels down to $0.3 \mathrm{~mm}$.

The next equation is due to Hall and Mudawar (2000)[7] who derived a statistical five-parameter correlation using a comprehensive database covering almost all the available literature. A total of 4860 data points were used and the rms error was $14.3 \%$. Data for diameters as low as $0.25 \mathrm{~mm}$ were successfully correlated.

Qu and Mudawar(2004)[8] proposed a correlation having a very low error. They originally compared the Katto-Ohno correlation against experimental data for water in the diameter range 1-3mm. For circular single channels, the accuracy was fairly high. However, they found that as CHF was approached, vapor backflow occurred in the upstream plenum as a result of flow instabilities. This resulted in CHF being more or less independent of inlet subcooling. The new correlation is aimed at addressing these issues. When compared against their data for water and R-113, flowing through 21 parallel $215 \times 821 \mu \mathrm{m}$ channels, the error was about $4 \%$.

Wojtan et al. (2006) [9] derived a simple correlation from R-134a and R-245fa data for 0.509 and $0.790 \mathrm{~mm}$ ID microchannels. The heated length varied from $20-70 \mathrm{~mm}$.

Zhang et al. (2006) [10] used an extensive database collated from 10 different laboratories and covering 2500 data points for water only for a parametric trend analysis and derived the correlation with all fluid properties specified at the inlet. Diameters as low as $0.33 \mathrm{~mm}$ have been considered.

Wojtan et al. (2006) used their own experimental data to compare the original Katto-Ohno correlation and felt the need for certain modifications. The analysis of their CHF data in single, circular and uniformly heated microchannels using a least squares approach led to a new fitting of the Katto-Ohno[11] curve. The Mean Absolute Error (MEA) is $7.6 \%$ and the recommended limit of applicability is $\rho_{v} / \rho_{l} \leq 0.15$ for a lack of data in the high reduced pressure range.

Kosar and Peles (2007)[12] concluded that CHF decreased with exit quality. However, this conclusion is hasty because the effect of quality at a constant mass flux was not specified. The decrease in CHF was mainly resulted from the decrease in mass flux. At constant heated length and mass flux, the CHF increased substantially with a reduction in tube diameter to $0.286 \mathrm{~mm}$ from $0.427 \mathrm{~mm}$. A similar trend was also observed by Qi et al. (2007). However, the Kosar and Peles correlation has poor predictive ability for both water and non-aqueous fluids. It overrates the experimental $B l$ values greatly with a large scatter for nonaqueous data, and under-predicts the experimental $B l$ values for water data.

Qi et al. (2007) [13] proposed a correlation that has been verified for aqueous data only.
Their other correlation [14] has been derived from flow-boiling data of nitrogen in channels of diameters $0.531-1.042 \mathrm{~mm}$. All properties are to be specified at the outlet.

Ong-Thome (2011) [15] have proposed an improved CHF correlation, based on a modification of the Wojtan et al. CHF correlation. The proposed correlation aims to fit the current CHF experimental data, the experimental CHF data of Wojtan et al. for circular channels with 0.51 and $0.79 \mathrm{~mm}$ internal diameters and square multichannels CHF data of Park for R134a, R236fa and R245fa with heated diameters $d_{h}=0.35$ and $0.88 \mathrm{~mm}$. The exponents for the density ratio, Weber number and the length/diameter ratio have all been modified to fit the data. Two new terms, namely $\left(d / d_{h}\right)$ and $\left(\mu_{l} / \mu_{v}\right)$ have been introduced to account for the macro-microscale confinement effect and the influence of viscosity on CHF. The new CHF correlation is valid for diameters between $0.35-3.04 \mathrm{~mm}$.

Wu et al. (2011) [16] outline a complicated nonetheless powerful algorithm for the derivation of their correlation. Heat flux is nondimensionalized using mass flux and latent heat of vaporization in boiling number $\mathrm{Bl}$. The heated equivalent diameter is used, reflecting the actual heating conditions. The following relationship appears to hold strongly

$$
\begin{aligned}
& B l_{c h f}=a_{1}\left(L_{h} / d_{h e}\right)^{a_{2}} \\
& a_{1}>0 \\
& a_{2}<0
\end{aligned}
$$

The exit quality is a function of three parameters: mass flux, inlet subcooling and CHF. Thus, the following functional form was proposed

$B l_{c h f}=a_{3} x_{e}^{a_{4}}$
$a_{3}, a_{4}>0$

By regressional analysis, the parameters were determined as:

$a_{1}=0.364$,

$a_{2}=1.19$

A new non-dimensional correlation is thus developed avoiding predictive discontinuities.

The final correlation of Table. $2[17,18]$ has also been derived by Wu et al. using logic along the similar lines as discussed above.

In this section we intend to discuss different correlations used for the prediction of CHF in micro and minichannels. We would also like to critically examine the suitability of the correlations and their range of applications. In this regard the excellent survey done by Revellin et al. (2009) should be mentioned. They have considered a large database containing 2996 data points from 19 different laboratories covering different types of fluids. Irrespective of the fluids a few general trends were observed. For saturated boiling CHF shows the following trends when the other parameters are kept constant.

-CHF increases with mass flux.

-CHF increases with the increase in $D$. A reverse trend is observed for subcooled boiling.

-CHF increases with decreasing heating length.

-CHF increases with subcooling.

-CHF increases with saturation pressure.

\section{PHYSICAL MECHANISM AND MECHANISTIC MODELS}

Inspite of the continued effort to reveal the physics of CHF in macrosystems, our understanding is only partial till date (Chung et al., 2011). It goes without saying that the mechanism of CHF in 
microchannel is more elusive and requires more time before any hypothesis can be established with confidence. Nevertheless certain facts are emerging due to the recent investigations.

One of the earliest efforts to consolidate the nature of CHF in microchannels is due to Bergles and Kandlikar (2005). Based on the literature available at that point of time they have made a number of interesting observations. These observations are as follows.

Single channel CHF data were very rare (at the time of their review). For parallel multi-microchannels the available CHF data were taken under unstable conditions. The critical condition was associated with the compressible volume instability upstream or with the parallel channel Ledinegg instability. This reduced the CHF values compared to those achievable under stable flow conditions.

The comment of Bergles and Kandlikar (2005) was based on the pioneering work of $\mathrm{Qu}$ and Mudawar (2003). In this work the investigators studied the flow boiling of de-ionized, deaerated water in a heat block consisting of twenty-one 215 X $821 \mu \mathrm{m}$ channels. The mass flux range was $86-368 \mathrm{~kg} / \mathrm{m}^{2} \mathrm{~s}$ with a variation of inlet temperature from $30-60^{\circ} \mathrm{C}$, while the outlet pressure was 1.13 bar. The authors reported a unique phenomenon as the CHF was approached. There was a reverse flow of the vapor mass from all the microchannels into the inlet plenum. Based on the description of the authors the phenomenon has been schematically reproduced in figure 7 .

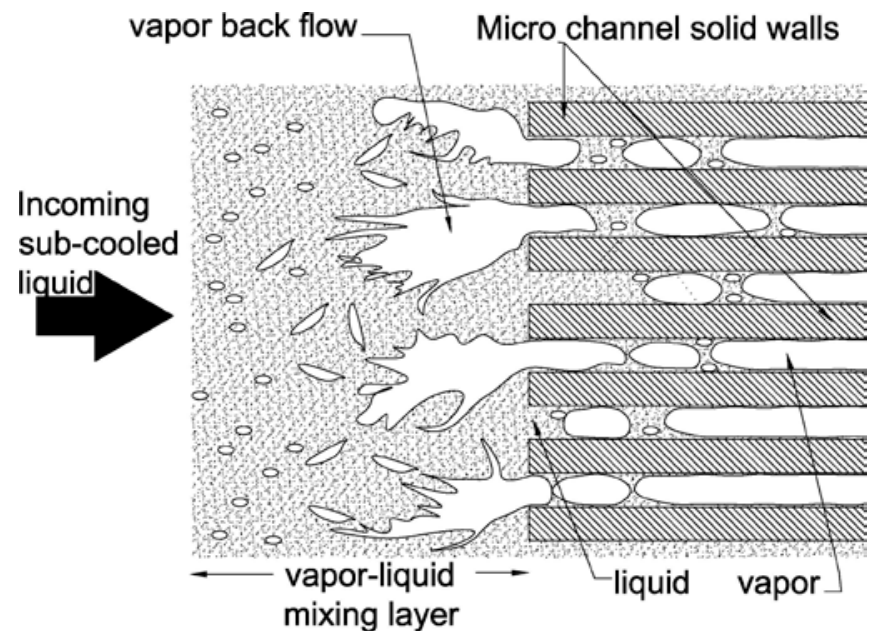

Fig. 7 Back flow of vapor mass into the inlet plenum during boiling in a multi microchannel block (Qu and Mudawar, 2003)

From the experimental data they have correlated the heat flux as

$\frac{q^{\prime \prime}}{G h_{f g}}=33.43 \times\left(\frac{\varrho_{g}}{\varrho_{f}}\right)^{1.11}\left(\frac{G^{2} L}{\sigma_{\ell}}\right)^{-0.21}\left(\frac{L}{d_{h}}\right)^{-0.36}$

The trend of the correlation is opposite to other common observation that CHF increases with decreasing channel diameter. Bergles and Kandlikar (2005) suggest that this anomaly is due the back flow of vapor which certainly blocks the inflow and reduces the inlet subcooling.

When there are a number of parallel channels connected to an inlet plenum, two types of instabilities are possible. Presence of a large compressible volume gives rise to constant volume instability (CVI) whose criteria is given by

$\left.\frac{\partial \Delta \rho}{\partial w}\right|_{C V I}=0$

Another type of instability is the excursive or Ledinegg instability which occurs due to the flow through a number of microchannels. This could be understood from the supply-demand curves of a pump-pipeline combination. The typical nature of the demand curve of a microchannel with boiling is responsible for such a typical static instability (Boure et. al. 1973). Termed as the Ledinegg or excursive instability (EI), its criterion for instability is given by

$$
\left.\frac{\partial \Delta \rho}{\partial w}\right|_{E I}=0
$$

Another important aspect of multi-microchannel block is the conjugate effect. A comprehensive analysis of CHF in such systems can be done considering the entire heat sink as a single unit. Though Bergles and Kandlikar (2005) commented on the scarcity of CHF data in single microchannels, many investigations have been conducted in narrow channels $(<3 \mathrm{~mm})$. In such channels, at relatively high mass flux, a unique phenomenon was observed (Fukuyama and Hirata, 1982; Hosaka et. al., 1990; Groeneveld, 1986).

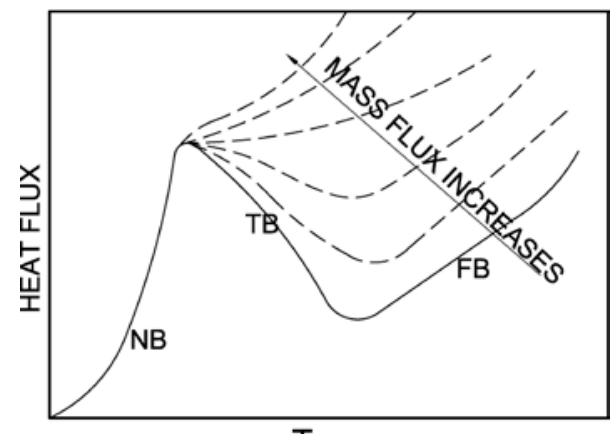

$T_{w}$

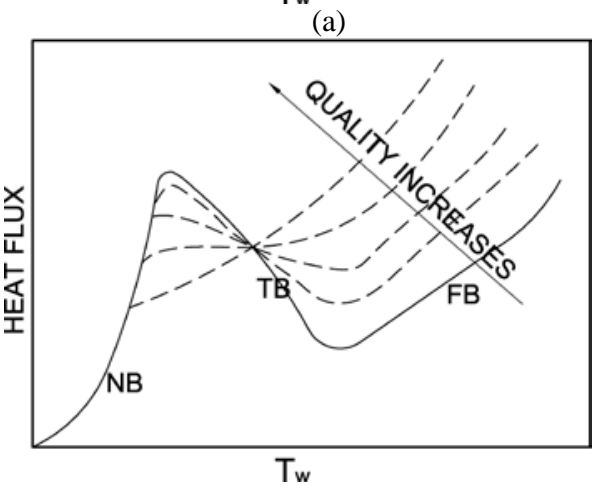

(b)

Fig. 8 Flow boiling curve: (a) variation with mass flux, (b) variation with quality.

The transition boiling curve has a positive slope contradicting the usual concept of critical heat flux. Based on the sketches provided by Groeneveld (1986) the probable boiling curves are shown in figure 8 for two cases, (i) variation of mass flux and (ii) variation of quality. Though, most of the microchannel applications are limited to not-veryhigh mass flux, care must be taken in their design and operation as the CHF behavior can deviate substantially from the usual trend.

Any mechanistic model of flow boiling should take the prevailing flow regimes into cognition. Aided by high speed photographic techniques, several researches have critically examined the flow regimes during boiling through microchannels. Kandlikar (2006) reported that during boiling, vapor phase may exist in the form of nucleating bubbles, dispersed bubbles, elongated bubbles and also in the core of annular flow. And liquid, on the other hand, can remain as bulk liquid and can appear as slugs, thin films on the channel wall or as dispersed droplets in the vapor stream. Accordingly, there could be a number of flow regimes. A unique phenomenon related to microchannel flow boiling is the rapidly expanding vapor bubbles. 
From high speed photography and from numerical simulation the existence of rapidly growing bubble in superheated liquid has been conceived. This causes a reverse flow of the liquid in the direction of the inlet manifold.

Harirchian and Garimella (2009a, 2011) reported five major flow regimes, namely bubbly, slug churn, wispy annular, annular and a post dryout regime of inverted annular flow. It may be noted that the observed flow regimes are not much different from those observed in large size conduits. The authors have reported an elaborate account on the influence of channel dimension and mass flux on the flow regimes. Nevertheless, a dedicated study on the relation between the flow regimes and CHF or dryout is still pending.

Kandlikar (2009) proposed a scale analysis based theoretical model for CHF. The model was an extension of the available theory of CHF but incorporated a force balance among the evaporation momentum, surface tension, inertia and viscous forces. The constants in the model were derived from the available experimental data.

Based on the available literature till date, it may be noted that the dryout during flow boiling has been associated with the elongated bubbles (Jacobi and Thome, 2002) or annular flow regime. Kandilkar (2010) depicted the local dry-patch formation (Figure 9) in elongated bubbles and discussed the role of micro-layer evaporation and the advancing and receding meniscus of an expanding bubble. Revellin and Thome (2008) suggested a mechanistic mode of CHF for flow boiling through heated microchannels. The foundation of their model is as follows. Based on the experimental observations it has been assumed that the CHF occurs in microchannel during annular flow due to film dryout. There could be two possibilities. At low mass fluxes dryout occurs when the liquid film is totally exhausted. This occurs at $\mathrm{x}=1.0$.

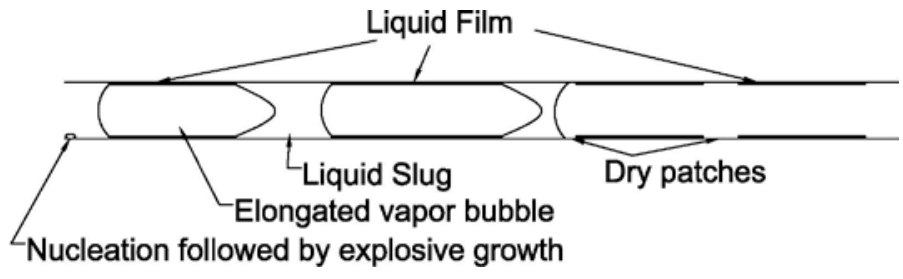

Fig. 9 Dry patch formation in elongated bubble (Kandlikar 2010)

At high mass flow rates vapor shear may overcome surface tension forces and succeed in removing the liquid film from the wall. For dryout to occur the average film thickness need not be zero, but the liquid film is wavy and the interfacial waves are large enough so that the troughs of them touch the wall. In this scenario dryout occurs at $\mathrm{x}<$ 1. These two situations are schematically depicted in figure 10 . The authors have separately considered one dimensional conservation equations for mass and momentum for the two phases. Further, the pressure difference across the phases was evaluated by the YoungLaplace equation. The set of differential equations are solved with suitable boundary conditions and the closure equation for wall friction. Additionally, the heights of the interfacial waves are determined considering the shear stress at the interface and the occurrence of Kelvin-Helmholtz instability. Final expression of the film thickness is obtained as

$$
\delta=C R\left(\frac{u_{v}}{u_{l}}\right)^{j_{1}}\left(\frac{\left(\rho_{l}-\rho_{V}\right)}{\sigma}\right)^{k_{1}}
$$

The values of $\mathrm{C}, \mathrm{j}_{1}$ and $\mathrm{k}_{1}$ are taken from experiment. The simulation stops when the above equation is satisfied at the outlet of the microchannel. The model has been validated for three different refrigerants (R-134a, R-245fa and R-113) from two different laboratories. More than $96 \%$ of the data could be predicted with an error band of $\pm 20 \%$, while the mean absolute error is $8 \%$.

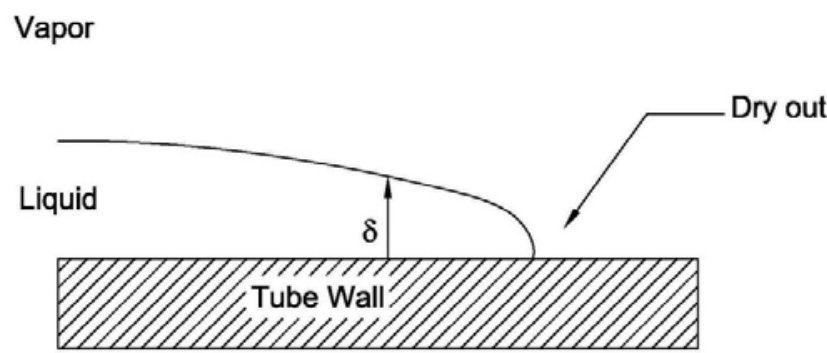

(a)

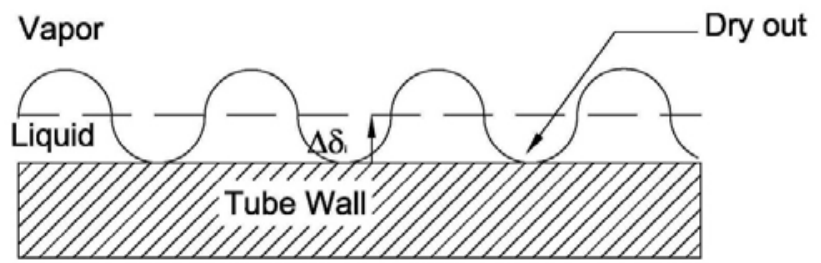

(b)

Fig. 10 Liquid film distribution in annular flow boiling (Ravellin and Thome, 2008): (a) smooth film, (b) wavy film

In a subsequent communication, Revellin et. al. (2008) extended the film dryout model. During flow boiling in microchannels, the vapor dry out quality $\left(\mathrm{x}_{\mathrm{do}}\right)$ depicts two different variations with the mass flux, G. For laminar dry out, $x_{\mathrm{do}}$ varies as $\mathrm{G}^{-\mathrm{j}}$ and for transition film dryout $x_{d o}$ varies with $G^{j}$, where $j$ is a positive index. The second type of variation was observed only for $\mathrm{CO}_{2}$ at high mass velocities. The authors have explained this difference in trend using the basic model of Revellin and Thome (2008). Finally, they commented that the behavior of $\mathrm{CO}_{2}$ is not radically different from other liquids. The appearant difference comes due to its higher reduced pressure used in many boiling situations.

Revellin and Thome (2009) further argued that though water exhibits a higher CHF compared to all the other fluids studied, it will not be a suitable candidate for the present application of electronic component cooling due to its very low saturation pressure at $30-40{ }^{\circ} \mathrm{C}$. Using the model already developed by them, they have critically examined the suitability of four different refrigerants for the same application. According to the order of merit from best to worst, they can be listed as follows: R-245fa, R-134a, R-236fa and FC-72. However R134a and R236fa give almost identical CHF values and the choice should depend on the design conditions. Further the authors have reiterated that a better design should conform to the following combination: (a) a shorter channel length, (b) a low saturation temperature, (c) high mass flux, (d) higher degree of subcooling, and (e) a larger dimension of the microchannel for the typical fluid.

Revellin et al. (2009) carried out a theoretical study on the optimization of a constructal based tree shaped microchannel network in a disc shaped heat sink. They have used the theoretical CHF model of Revellin and Thome (2008). It has been observed that the coupling of pumping power with the base CHF leads to a different design. Finally, they commented that in the design, inclusion of a high complexity need not result in the best design.

Kosar (2009) constructed a simple model of CHF for saturated flow boiling. It is postulated that during saturated boiling, the flow regimes transform from bubbly to slug and then to spray annular flow pattern which is characterized by a thin annular liquid film at the wall and liquid droplets at the vapor core as shown in figure 11, according to the description of Kosar. It may be noted that figure 11 is much similar to the description of flow regimes during flow boiling in heated vertical channels of larger dimensions. Or in other words, in case of microchannels, stratification due to gravity may be neglected. The complete evaporation of the liquid film gives rise to dry out. The model is based on simple algebraic relationships of mass and energy balance. 
The model was tested for a range of mini and microchannels $\left(0.223 \mathrm{~mm}<\mathrm{d}_{\mathrm{h}}<3.1 \mathrm{~mm}\right)$, both of round and rectangular cross section, for fluids like water and refrigerants (R-123, R-113, R-134a and R-245fa). 151 experimental data cover a range of mass velocities from 50 to 1600 $\mathrm{Kg} / \mathrm{m}^{2} \mathrm{~s}$ and pressure $101-888 \mathrm{kPa}$. An overall mean absolute error of $25.8 \%$ was noted. Better prediction was obtained for channels with thin walls and for flow without instability.

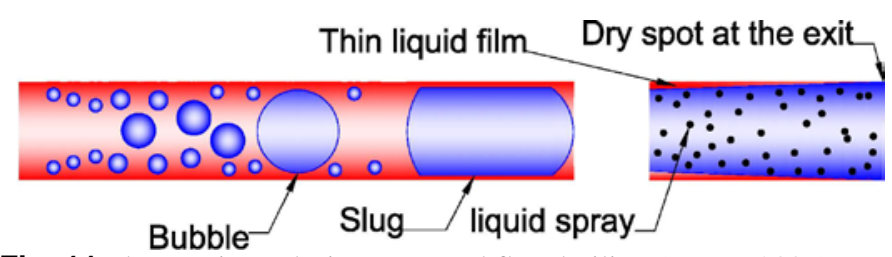

Fig. 11 Flow regimes during saturated flow boiling (Kosar, 2009)

Kuan and Kandlikar (2008) proposed another mechanistic model of critical heat flux based on force balance at the interface of a vapor plug in a microchannel. Considering three different forces namely momentum force, inertia force, and surface force; they could obtain a closed formed expression for CHF in terms of the contact angle $\theta$ and the channel height $b$ :

$$
q^{\prime \prime}=h_{f g} \sqrt{\rho_{g}} \sqrt{\frac{2 \sigma \cos \theta}{b}+\frac{G^{2}}{2 \bar{\rho}}}
$$

The model could predict the trend of CHF and was correlated well with the experimental data of the authors.

\section{PRESENT STATE OF UNDERSTANDING AND PREDICTION OF CHF IN MICROCHANNEL}

In this section the present state of understanding and prediction capacity for CHF during flow boiling through mini and microchannels has been briefly summarized.

The studies on this topic can be briefly classified into two categories. Early studies on single channel narrow metallic tubes $(1 \mathrm{~mm} \leq D \leq 3 \mathrm{~mm}$ ) were made with high flow rates and relatively larger tube length due to the importance of high heat flux cooling particularly for nuclear reactors. Mainly water was considered as the coolant though some studies on liquid nitrogen, helium (Katto and Yakoya, 1984) and different refrigerants (Kuan and Kandlikar, 2006, Lin et al., 2001, Warrier et al., 2002) as well as $\mathrm{CO}_{2}$ (Pettersen, 2004) were reported. These investigations are important for nuclear reactors, particularly for the cooling of the first wall of fusion reactors. The studies in recent years are pertaining to heat sinks mainly targeted to the cooling of electronic components. For this application, investigations have been made in both microtubes and microchannels of rectangular crosssections. Copper, stainless steel as well as silicon have been taken as the channel material. A large number of studies have been made in multichannel blocks. All the heat sink related studies are restricted to a low value of mass velocity and a relatively low value of length-todiameter ratio of the tubes or channels.

From the experiments the following trends have emerged:

1. CHF increases with mass flux

2. CHF increases with the increase in channel hydraulic diameter. This is a common trend with saturated boiling. However, the trend is reverse for subcooled boiling.

3. CHF increases with the increase in $L / D$ ratio.

4. CHF increases with the increase in saturation temperature.

5. There is an increase in CHF with the increase in degree of subcooling at channel inlet.

All the above observations follow from the fundamental physics. However, point 2 needs some explanation which has been provided elsewhere in the paper.
Over the years the experimental techniques for boiling in microchannel has matured as there has been a substantial improvement of the techniques for the fabrication of microchannels. With the help of micro machining and non-conventional manufacturing techniques (Kandlikar and Grande, 2003) prototype of microchannel heat sinks with suitable inlet and outlet manifolds are fabricated. In many of the experimental facilities, specially designed heating elements are embedded. Microthermocouples are also employed. High speed photography with a high magnification has been adopted in many studies. This has helped to reveal the flow regimes. As a consequence, now a reasonable idea regarding the flow regime s during microchannel boiling exists.

Quite some time back it was understood that CHF could be low in a multichannel heat sink due to flow oscillation and reverse flow. It was also suggested that the incorporation of some flow restriction at the inlet of the channels will improve the situation at the cost of extra pumping power (Kosar(2009)).

Over the years a number of correlations have been used for the prediction of CHF in microchannels. It is interesting to note that some of the correlations which were not specifically developed for microchannels exhibit good agreement with microchannel data. The correlation by Katto (1978) and Katto and Ohno (1984) fall in that category. On the other hand, a host of new correlations have also been developed. On the average, the correlations can predict the experimental data within $\pm 30 \%$ range.

The effort for modeling CHF in microchannel is still in its infancy. Most of the postulations are based on dryout of thin annular film. All the models are highly idealized and need experimental data for their closure. Many of the models are capable of predicting the correct trend of CHF variation with different parameters.

\section{GRAY AREAS AND RESEARCH NEEDS}

Microchannel cooling has a great potential as miniaturization is the call of the day. Successful adoption of microchannel boiling in the future cooling technologies requires reliable methods of prediction not only for boiling heat transfer but also for CHF. The forward leap from single phase liquid cooling to cooling with evaporation or boiling can be made possible only through a well-planned research programme which addresses the gray areas in this field. Some of these areas are iterated below.

In a practical cooling system, a single microchannel is rarely expected to be used. However, the phenomenon of boiling in general and CHF in particular is to be studied through single microchannels. Kandilkar (2006) observed that for cooling with boiling heat transfer, normally channels less than $1 \mathrm{~mm}$ diameter have rarely been chosen. This is due to the dearth of confidence in using microchannels of narrower dimensions for this typical transport phenomenon. Further research is needed in this direction.

Conducting experimental study for boiling in single micron size channel possesses a number of practical difficulties. Correct assessment of temperature and heat flux is difficult due to the limitations of measurement. In spite of careful efforts, the strong conjugate effect cannot be neglected. Therefore, often the estimation of heat flux and surface temperature only through measurements is not reliable. Analysis based on inverse conduction is expected to enhance the accuracy of the derived data.

Flow visualization is extremely important. Though different boiling regimes have been reported in recent times from high speed photography, yet a lot more is to be done. Visualization is a real challenge for microchannel boiling. For microtubes, simultaneous visualization and parametric measurements are difficult to achieve. Innovative solutions are needed in this regard. Use of transparent thin film heating element over a quartz tube may be a viable solution and should be tried. In case of rectangular channels, visualization is possible if the top cover of the channel is made transparent and arrangements are made for adequate illumination. However, this violates the condition of uniformly heated channels. Further, the effect of inlet and outlet geometry on microchannel boiling needs to be assessed correctly. 
Bergles and Kandlikar (2005) have provided important suggestions regarding the measures to be taken for successful data reduction from microchannel experiments.

Though single channel experiments are necessary, the need for further experimentations in multichannel heat sinks cannot be overlooked. The two instabilities mentioned by Bergles and Kandlikar (2005), namely the instability due to the presence of upstream compressible volume and the excursive instability, reduce the CHF. These two instabilities should be studied thoroughly in connection with multi microchannel. The study should address two aspects. Firstly, one needs to know the extent by which these instabilities reduce CHF. Efforts should also be there to decrease margin of such instabilities by the proper design of the system.

A survey of literature on flow boiling through microchannels reveals two distinct classes of investigations. A large number of studies have been made to understand CHF at high mass flux (Daleas and Bergles, 1965; Hosaka et al., 1990; Katto and Yokoya, 1984; Nariai et al., 1987; Celata et al., 1993). These studies used $D_{h}$ of $1-3 \mathrm{~mm}$ for heated single channels, mostly tubes. Such applications are relevant for the cooling of the first wall of fusion reactors.

On the other hand, in recent times, most of the works on microchannel boiling are directed to heat sink design and involve low mass flux. Further, the range of $d_{h}$ is submillimetric and investigation of multi-channel with non-circular cross-section is a common trend. Obviously, there is a need for a comprehensive scheme of experiments which will encompass a large range of mass flux variation, variation of channel dimension and shape as well as single and multichannel keeping the rest of the test matrix fixed as far as possible.

So far, only two geometries of the microchannel have been considered in the study of flow boiling. They are round and rectangular. However, both for the applications of heat sink and high mass flux cooling, one cannot rule out the use of other geometries. Experimental studies are needed in these geometries to enhance the level of confidence in the prediction of CHF.

Surface roughness is expected to have a significant influence on CHF. Earlier, it has been shown that CHF can be enhanced by manipulating surface roughness. Quantification and manipulation of surface roughness in microchannels is a challenge. Experiments must be devised to explore the effect of surface roughness on the CHF in microchannels. Same systematic studies should be planned to explore the effect of dissolved gas in the liquid and its boiling characteristics.

A large number of studies on microchannels boiling have been done using a number of refrigerants. In all the cases pure refrigerant has been taken as the test fluid. If the refrigerant flow is driven by a compressor (as in refrigeration cycle), the refrigerant mixes with the lubricants. Studies are pending on the CHF of oil-refrigerant mixture through narrow channels. Effects of other additives on the CHF of microchannel flow boiling are equally unknown. For large sized tubes different augmentation techniques have been adopted (Chang and Baek, 2003) to enhance CHF. This includes surface modification, use of additives in the base fluid etc. similar studies are needed for microchannels. In this regard the use of nanofluid (Vafei and Wen, 2010) may be mentioned.

For tubes of larger dimensions extensive efforts have been made to enhance the critical heat flux. The techniques for such enhancements covers a wide range like surface modification, twisted tape insert, application of electric and rotational field, solid and liquid additives for the boiling liquid etc. In recent time use of nanofluids has been tried by a large number of researchers for this purpose in conventional systems. For the augmentation of CHF in microchannels rarely any investigation has been done. One effort in this direction is due to Vafai and Wen (2010). They have used alumina nanofluids in a horizontal microchannel and observe around 51\% increase in CHF for $0.1 \%$ addition of solid by volume. Obviously, a greater effort should be spent for the augmentation of CHF in microchannel.

A major initiative needs to be taken as far as the modeling of CHF through microchannels is concerned. So far, only a limited effort has been made to develop some mechanistic models of CHF in microchannels. These models are extensions of the existing models suitable for macro systems based on the assumed mechanism of dry out. These models have shown some success in predicting the experimental data. The model of Revelin and Thome (2008) may be mentioned in this regard. However, all these models are highly idealized and too specific. As they are low order models and need closures from experiment, standalone robust models critically verified by an extensive data bank of reliable experiments are the need of the day.

With the growing computational power and the better understanding of the physical phenomena, CFD has become a very powerful tool for prediction. In recent times reasonable success has been achieved in the modeling of boiling heat transfer in macro systems (Mukherjee and Dhir, 2004; Liao et al., 2004; Tomar et al., 2005; Genske and Stephan, 2006; Mukherjee and Kandilkar, 2007; Son and Dhir, 2008; Wu and Dhir; 2010). This has been achieved by direct numerical simulation where separate set of conservation equations are solved for each of the phases and a suitable algorithm is adopted for the modeling of the interface. In recent time computational techniques like molecular dynamics and Lattice Boltzmann method are also used to model different intricate processes of bubble growth, coalescence and moving contact line phenomena. A good survey of the available literature may be found in Chung et al. (2011). Unfortunately, such endeavors have not been taken to model CHF in microchannels. Researchers should pay attention to this. Through a combination of the bulk flow modeling and modeling for the micro layer, it is expected that the transport processes during CHF in micro-channels will be better understood.

Finally, it should be appreciated that CHF is not an isolated phenomenon. In case of flow boiling, it is regime dependent. It could be regarded as an extreme development of the nucleate boiling process or dry out of a gradually thinning evaporating film, or a phenomenon triggered by the local dry patch formation over the heated surface. In case of microchannel, the process is further complicated by the wall confinement. In any case, an appropriate model of flow boiling should be able to capture CHF. For model development, this should be the ultimate goal of future research.

\section{NOMENCLATURE}

$\begin{array}{ll}\text { a } & \text { parameter } \\ A & \text { Cross-sectional area }\left(m^{2}\right) \\ B l & \text { Boiling number } q /\left(G h_{l v}\right) \\ B o & \text { Bond number } g\left(\rho_{l}-\rho_{g}\right) d_{h}^{2} / \sigma \\ c & \text { Specific heat capacity }(\mathrm{J} / \mathrm{kg}) \\ C a & \text { Capillary number }(\mu \mathrm{G} / \mathrm{p} \sigma) \\ C o & \text { Confinement number }(1 / \sqrt{B o}) \\ d & \text { Diameter(mm) } \\ g & \text { Acceleration due to gravity }\left(\mathrm{m} / \mathrm{s}^{2}\right) \\ G & \text { Mass flux }\left(\mathrm{kg} / \mathrm{m}^{2} \mathrm{~s}\right) \\ h & \text { Enthalpy }(\mathrm{J} / \mathrm{kg}) \\ k & \text { Thermal conductivity }(\mathrm{W} / \mathrm{mK}) \\ L & \text { Length(m) } \\ p & \text { Pressure }(\text { Pa) } \\ q & \text { Heat flux }\left(W / m^{2}\right) \\ \text { Re } & \text { Reynolds' number }(\rho u d / \mu) \\ T & \text { Temperature }(\mathrm{K}) \\ u & \text { Velocity }(\mathrm{m} / \mathrm{s}) \\ W & \text { Mass flow rate }(\mathrm{kg} / \mathrm{s}) \\ W e & \text { Weber number }\left(G^{2} d_{h} / \rho \sigma\right) \\ x & \text { Vapor quality } \\ Y & \text { Shah parameter }\end{array}$


Greek symbols:

$\begin{array}{ll}\delta & \text { Film thickness/ wave thickness } \\ \rho & \text { Density }\left(\mathrm{kg} / \mathrm{m}^{3}\right) \\ \bar{\rho} & \text { Average density }\left(\mathrm{kg} / \mathrm{m}^{3}\right) \\ \mu & \text { Dynamic viscosity }(\mathrm{Pa}-\mathrm{s}) \\ \sigma & \text { Surface tension }(\mathrm{N} / \mathrm{m})\end{array}$

Subscripts:

ch Channel

chf Critical heat flux

cr Critical

D Diameter

e $\quad$ Exit

eq;o Equilibrium value at inlet

$f \quad$ Saturated liquid

fg liquid to gas

h heated

hor Horizontal

i Interfacial

in Inlet

l Saturated liquid

lo $\quad$ Liquid only

lv $\quad$ Liquid to vapor

$m \quad$ Mean

o Outlet

$r \quad$ Reduced w.r.t. critical quantity

sat Saturated

sub Subcooling

tab Look-up table

$v \quad$ Saturated vapor

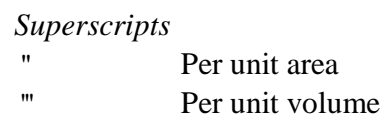

\section{REFERENCES}

Agostini et al., 2007, State of the Art of High Heat Flux Cooling Techology, Heat Transfer engineering, 28 (4), 258-281, DOI: http://dx.doi.org/10.1080/01457630601117799.

Agostini B., Revellin R, Thome J. R., Fabbri M, Michel M, Calmi D, Kloter U.,2008, High Heat Flux Flow Boiling In Silicon Multimicrochannels - Part III: Saturated Critical Heat Flux of R236fa and Two-phase Pressure Drops, International Journal of Heat and Mass Transfer, 51, 5426-5442,

DOI: http://dx.doi.org/10.1016/j.jjheatmasstransfer.2008.03.00 .

Aoki, S., Inoue, A., Aritomi, M., Sakamoto, Y., 1982, Experimental Study Within on the Boiling Phenomena a Narrow Gap, International Journal of Heat and Mass Transfer, 25 (7), 985 - 990. DOI: http://dx.doi.org/10.1016/0017-9310(82)90073-4

Bar-Cohen, A., K. Geisler, Rahim E., 2008, Pool and Flow Boiling in Narrow Gaps - Application to 3D Chip Stacks, Proc of Fifth European Thermal-Sciences Conference.

Barnea, D., Luninski, Y., Taitel, Y., 1983. Flow pattern in horizontal and vertical two phase flow in small diameter pipes. Can. J. Chem. Eng. 61, 617-620, DOI: http://dx.doi.org/10.1002/cjce.5450610501.

Bergles, A. E., 1962, Subcooled Burnout in Tubes of Small Diameter, ASME Paper 63-WA-182.
Bergles, A. E., 1992, What is the Real Mechanism of CHF in Pool Boiling. In Pool and External Flow Boiling (Edited by Dhir, V. K., and Bergles, A. E.), ASME, New York, 165-170.

Bergles, A. E., Kandlikar, S. G., 2005, On the Nature of Critical Heat Flux in Microchannels, Journal of Heat Transfer, 127, 101-107, DOI: http://dx.doi.org/10.1115/1.1839587.

Bergles, A. E., Lienhard V, J. H., Kendall, G. E., Griffith, P., 2010. Boiling and Evaporation in Small Diameter Channels, Heat Transfer Engineering, 24, 1, 18-40 DOI: http://dx.doi.org/10.1080/01457630304041.

Bhusan, S., Ghosh, S., Das, G., Das, P., 2009, Rise of Taylor Bubbles through Narrow Rectangular Channels, Chemical Engineering Journal, 155(1-2), 326 - 332.

DOI: http://dx.doi.org/10.1016/j.cej.2009.07.006.

Boure, J. A., Bergles, A. E., Tong, L. S., 1973, Review of two phase flow instability, Nuclear Engineering and Design, 25, 165 - 192. DOI: http://dx.doi.org/10.1016/0029-5493(73)90043-5.

Bower, M. B., and Mudawar, I., 1994, High flux boiling in low flow rate, low pressure drop mini-channel and micro-channel heat sinks, International Journal of Heat and Mass Transfer, 37 (2), 321-332. DOI: http://dx.doi.org/10.1016/0017-9310(94)90103-1

Celeta, G. P., Cumo, M., and Mariani, A., 1993, Burnout in Highly Subcooled Water Flow Boiling in Small Diameter Tubes, International Journal of Heat and Mass Transfer, 36, 1269 - 1285. DOI: http://dx.doi.org/10.1016/S0017-9310(05)80096-1

Celata, G. P., and Mariani, A., 1999, CHF and Post-CHF (Post-Dryout) Heat Transfer, Chapter 17, Handbook of Phase change, Boiling and Condensation, Edited by Kandlikar, S. G., Shoji, M., and Dhir, V. K., Taylor and Francis, New York, 443-493.

Chang, S. H., Baek, W. P. 2003. Understanding, Predicting and Enhancing Critical Heat Flux, The $10^{\text {th }}$ international Topical Meeting on Nuclear Reactor Thermo-hydraulics (NURETH-10), Seoul

Chung, J. N., Chen, T., Maroo, S. C., 2011, A review of recent progress on Nano/Micro-scale Nucleate Boiling Fundamentals, Frontiers in Heat and Mass Transfer, 2, $023004 . \quad$ DOI: http://dx.doi.org/10.5098/hmt.v2.2.3004.

Daleas, R. S., and Bergles, A. E., 1965, Effects of Upstream Compressibility on Subcooled Critical Heat Flux, Paper 65 - HT - 67, ASME, New York.

Dhir, V. K., and Liaw, S. P., 1989, Framework for a Unified Model for Nucleate and Transition Pool Boiling, ASME Journal of Heat Transfer, 111 (3) 739-746, DOI: http://dx.doi.org/10.1115/1.3250745

Fukuyama, Y., Hirata, M., 1982, Boiling Heat Transfer Characteristics with High Mass Flux and Disappearance of CHF Following to DNB, Proc. $7^{\text {th }}$ International Heat and Mass Transfer Conference, 4, 273 278.

Genske, P. and Stephan, K., 2006, Numerical simulation of heat transfer during growth of single vapor bubbles in nucleate boiling, International Journal of Thermal Sciences, 45(3), 299-309. DOI: http://dx.doi.org/10.1016/j.ijthermalsci.2004.07.008

Ghiaasiaan, S. M., Abdel-Khalik, S. I., 2001, Two-phase Flow in Microchannels, Advances in Heat Transfer, 34, 145-254

Groeneveld, D.C., Cheng, S.C., Doan, T., 1986, 1986 AECL-UO Critical Heat Flux Lookup Table, Heat Transfer Eng. 7, 46-62. DOI: http://dx.doi.org/10.1080/01457638608939644

Groeneveld, D. C. 1986. The onset of dry sheath condition - A New Definition of Dry-out, Nuclear Engineering and Design, 92, 135-140, DOI: http://dx.doi.org/10.1016/0029-5493(86)90241-4 
Ha, S. J., No, H. C., 1998, A Dry-spot Model of Critical Heat Flux in Pool and Forced Convention Boiling, International Journal of Heat and Mass Transfer, 41, 303-311, DOI: http://dx.doi.org/10.1016/S0017$\underline{9310(97) 00140-3}$

Ha, S. J., No, H. C., 2000, A Dry-spot Model of Critical Heat Flux Applicable to Both Pool Boiling and Subcooled Forced Convention Boiling, International Journal of Heat and Mass Transfer, 43, 241-250, DOI: http://dx.doi.org/10.1016/S0017-9310(99)00135-0

Hall, D. D., Mudawar, I., 2000, Critical heat flux (CHF) for water flow in tubes-II: Subcooled CHF correlations, International Journal of Heat and Mass Transfer 43, 2605-2640. DOI: http://dx.doi.org/10.1016/S0017-9310(99)00192-1

Haramura Y., and Katto, Y., 1983, A New Hydrodynamic Model of Critical Heat Flux Applicable to Both pool and Forced Convection Boiling on Submerged Bodies in Saturated Liquids, International Journal of Heat and Mass Transfer, 26, 379-399, DOI: http://dx.doi.org/10.1016/0017-9310(83)90043-1

Harirchian, T., Garimella, S. V., 2009a, The Critical Role of Channel Dimension, Heat Flux, and Mass Flux on Flow Boiling Regimes in Microchannel, International Journal of Multiphase Flow, 35, 349-362, DOI: http://dx.doi.org/10.1016/j.ijmultiphaseflow.2009.01.003

Harirchian, T., Garimella, S. V., 2009b, The Critical Role of Channel Cross-Sectional Area in Microchannel Flow Boiling Heat Transfer, International Journal of Multiphase Flow, 35, 904-913, DOI: http://dx.doi.org/10.1016/j.ijmultiphaseflow.2009.06.005

Harirchian, T., Garimella, S. V., 2011, Boiling Heat Transfer and Flow Regimes in Microchannels-A Comprehensive Understanding, Journal of Electron Packaging, 133, 1, 011001, DOI: http://dx.doi.org/10.1115/1.4002721

Hetsroni G., Mosyak A., Pogrebnyak E., Segal Z., 2006, Periodic Boiling in Parallel Micro-channels at Low Vapor Quality, International Journal of Multiphase Flow, 32, 1141-1159, DOI: http://dx.doi.org/10.1016/j.ijmultiphaseflow.2006.06.005

Hosaka, S., Hirata, M., Kasagi, N., 1990, Forced Convective Subcooled Boiling Heat Transfer and CHF in Small Diameter Tubes, Proc. $9^{\text {th }}$ International Heat and Mass Transfer Conference, 2, 129 - 134

Jacobi, A. M., Thome, J. R. 2002. Heat Transfer Model for Evaporation of Elongated Bubble Flows in Microchannels, Journal of Heat Transfer 124. 1131-1136, DOI: http://dx.doi.org/10.1115/1.1517274

Kandlikar, S. G. 2001a. A Theoretical Model to Predict Pool Boiling CHF Incorporating Effects of Contact Angle and Orientation, Journal of Heat Transfer, 123, 6, 1071-1079

DOI: http://dx.doi.org/10.1115/1.1409265

Kandlikar, S. G. 2001b, Critical Heat Flux in Subcooled Flow BoilingAn Assessment of Current Understandings and Future Directions for Research, Multiphase Science and Technology, 13, 3, 207-232,

Kandlikar, S. G, and Grande, W. J., 2003, Evolution of Microchannel Flow Passages - Thermohydraulic Performance and Fabrication Technology, Heat Transfer Engineering, 24 (1), 3 - 17. DOI: http://dx.doi.org/10.1080/01457630304040

Kandlikar S. G., 2006, Effect of Liquid - Vapor Phase Distribution on The Heat Transfer Mechanisms During Flow Boiling in Minichannels and Microchannels, Heat Transfer Engineering, 27 (1), 4 - 13. DOI: http://dx.doi.org/10.1080/01457630500341607

Kandlikar, S. G. 2009. A Scale Analysis Based Theoretical Force Balance Model For Critical Heat Flux (CHF) During Saturated Flow Boiling in Microchannels and Minichannels, Proceedings of ASME 2009 Second Micro/Nanoscale Heat and Mass Transfer International Conference, Shanghai, China.
Kandlikar, S. G. 2010. Similarities and Differences between Flow Boiling in Microchannels and Pool Boiling, Heat Transfer Engineering, 31:3, 159-167, DOI: http://dx.doi.org/10.1080/01457630903304335.

Katto, Y., Yokoya, S., 1984, Critical Heat Flux of Liquid Helium (I) in Forced Convection Boiling, International Journal of Multiphase Flow, 10, 401- 403. DOI: http://dx.doi.org/10.1016/0301-9322(84)90052-1

Katto, Y. 1978. A Generalized Correlation of Critical Heat Flux for the Forced Convection Boiling in Vertical Uniformly Heated Round Tubes, International Journal of Heat and Mass Transfer, 21, pp. 1527-1542. DOI: http://dx.doi.org/10.1016/0017-9310(78)90009-1

Katto, Y., Yokoya, S., 1984, Critical Heat Flux of Liquid Helium (I) in Forced Convection Boiling, International Journal of Multiphase Flow, 10, 401- 403. DOI: http://dx.doi.org/10.1016/0301-9322(84)90052-1

Katto, Y., Ohno, H., 1984, An Improved Version of the Generalized Correlation of Critical Heat Flux for the Forced Convective Boiling in Uniformly Heated Vertical Tubes, International Journal of Heat and Mass Transfer, 27, 1641 - 1648.

DOI: http://dx.doi.org/10.1016/0017-9310(84)90276-X

Katto, Y. 1994. Critical Heat Flux, International Journal of Multiphase Flow, 20. 53-90, DOI: http://dx.doi.org/10.1016/0301-9322(94)90070-1

Kew, P. A., Cornwell, K., 1997, Correlations for Prediction of Flow Boiling Heat Transfer in Small-diameter Channels, Applied Thermal Engineering, 17, 705-715, DOI: http://dx.doi.org/10.1016/S13594311(96)00071-3

Kim, Y. H., Kim, S. J., Noh, S. W., Suh, et a., 2003, Critical Heat Fluxi in Narrow Gap in Two-dimensional Slices under Uniform Heating Condition, Transactions of the 17th International Conference on Structural Mechanics in Reactor Technology (SMiRT 17), Prague, Czech Republic.

Kim, J. J., Kim, Y. H., Kim, S. J., et al., 2004, Boiling Visualization And Critical Heat Flux Phenomena In Narrow Rectangular Gap, Fourth Japan-Korea Symposium On Nuclear Thermal Hydraulics and Safety

Kosar, A., 2009, A Model to Predict Saturated Critical Heat Flux in Minichannels and Microchannels, International Journal of Thermal Sciences, 48, 261-270,

DOI: http://dx.doi.org/10.1016/j.ijthermalsci.2008.08.008

Kosar, A., Peles, Y., 2007, Critical heat flux of R-123 in silicon-based microchannels, Journal of Heat Transfer 129, 844-851. DOI: http://dx.doi.org/10.1115/1.2712852

Kuan, W.K., Kandlikar, S.G., 2006, Experimental Study on Saturated Flow Boiling Critical Heat Flux in Microchannels, in: Fourth International Conference on Nanochannels, Microchannels and Minichannels, Limerick, Ireland.

Kuan, W.K., Kandlikar, S.G., 2008, Experimental Study and Model on Critical Heat Flux of Refrigerants-123 and Water in Microchannels, $J$. Heat Transfer, 130 (3), 1-5. 034503.

DOI: http://dx.doi.org/10.1115/1.2804936

Lee J., Mudawar I., 2005, Two-Phase Flow in High-Heat-Flux Microchannel Heat Sink for Refrigeration Cooling Applications: Part IIHeat Transfer Characteristics, International Journal of Heat and Mass Transfer, 48, 941-955, DOI:http://dx.doi.org/10.1016/10.1016/j.ijheatmasstransfer.2004.09.01 $\underline{9}$

Liao, J., Mei, R. and Klausner, J.F., 2004, The influence of the bulk liquid thermal boundary layer on saturated nucleate boiling, International Journal of Heat and Fluid Flow, 25(2), 196-208.

DOI: http://dx.doi.org/10.1016/j.ijheatfluidflow.2003.11.012

Liaw, S. P., Dhir V. K., 1989, Void fraction measurements during saturated pool boiling of water on partially wetted vertical surfaces, 
Trans. ASME J. Heat Transfer, 111 (3) , 731-738, DOI: http://dx.doi.org/10.1115/1.3250744

Lin, S., Kew, P. A., Cornwell, K., 2001, Flow Boiling of Refrigerant R141b in Small Tubes, Transactions of IChemE, Part A 79. 417-424

Lienhard, J. H., and Dhir, V. K., 1973, extended Hydrodynamic Theory of the Peak and Minimum Pool Boiling Heat Fluxes, NASA CR-2270, Contract No. NGL 18-001-035

Mauro A. W, Thome J. R, Toto D, Vanoli G. P, 2010, Saturated Critical Heat Flux in a Multi-Microchannel Heat Sink Fed by a Split Flow System, Experimental Thermal and Fluid Science, 34, 81 - 92, http://dx.doi.org/10.1016/j.expthermflusci.2009.09.005

Moriyama, K., Inoue, A., 1992, The Thermodynamic Characteristics of the Two-Phase Flow in Extremely Narrow Channels, Heat Transfer Japanese Research 21 (8) 823-856.

Mukherjee, A. and Dhir, V.K., 2004, Study of lateral merger of vapor during nucleate pool boiling, Journal of Heat Transfer-Transactions of the Asme, 126(6), 1023-1039.

DOI: http://dx.doi.org/10.1115/1.1834614

Mukherjee, A. and Kandlikar, S.G., 2007, Numerical study of single bubbles with dynamic contact angle during nucleate pool boiling, International Journal of Heat and Mass Transfer, 50(1-2), 127-138. DOI: http://dx.doi.org/10.1016/j.ijheatmasstransfer.2006.06.037

Nariai, H., Inasaka, F., and Shimuara, T., 1987, Critical Heat Flux of Subcooled Flow Boiling in Narrow Tubes, ASME/JSME Thermal Engineering Joint Conf. (1987), 5, 455 - 462

Nukiyama, S., 1966, The Maximum and Minimum Values of the Heat Q Transmitted from Metal to Boiling Water Under Atmospheric Pressure, International Journal of Heat and Mass Transfer, 9, 14191433, DOI: http://dx.doi.org/10.1016/0017-9310(66)90138-4

Ong, C. L., Thome, J. R. 2011. Macro-to-Microchannel Transition in Two-Phase Flow: Part 2 - Flow Boiling Heat Transfer and Critical Heat Flux. Experimental Thermal and Fluid Science 35 (2011) 873-886. DOI: http://dx.doi.org/10.1016/j.expthermflusci.2010.12.003

Park J. E., Thome J. R., 2010, Critical Heat Flux in Multi-Microchannel Copper Elements with Low Pressure Refrigerants, International Journal of Heat and Mass Transfer, 53, 110 - 122, DOI: http://dx.doi.org/10.1016/j.ijheatmasstransfer.2009.09.047

Pettersen, J., 2004, Flow Vaporization of $\mathrm{CO}_{2}$ in Microchannel Tubes, Exp. Therm. Fluid Sci., 28, 111-121. DOI: http://dx.doi.org/10.1016/S0894-1777(03)00029-3

Qi, S. L., Zhang, P., Wang, R. J., et al., 2007, Flow Boiling of Liquid Nitrogen in Microtubes: Part II - Heat Transfer Characteristics and Critical Heat Flux, Int. J. HeatMass Transfer, 50, 5017-5030. DOI: http://dx.doi.org/10.1016/j.ijheatmasstransfer.2007.08.017

Qu, W., Mudawar, I., 2003, Measurement and Correlation of Critical Heat Flux in Two-Phase Micro-channel Heat Sinks, International Journal of Heat and Mass Transfer 47 2045-2059. DOI: http://dx.doi.org/10.1016/j.ijheatmasstransfer.2003.12.006

Qu, W., Mudawar, I., 2004, Measurement and correlation of critical heat flux in two-phase micro-channel heat sinks, International Journal Heat and Mass Transfer 47, 2045-2059.

DOI: http://dx.doi.org/10.1016/j.ijheatmasstransfer.2003.12.006

Revellin, R. 2005. Experimental Two-Phase Fluid Flow in Microchannels, Ph.D. thesis, Ecole Polytechnique Federale de Lausanne (EPFL), available at: http://library.epfl.ch/en/theses/?nr=3437

Revellin, R., Thome, J. R., 2008, A theoretical Model for the Prediction of the Critical Heat Flux in Heated Microchannels, International
Journal of Heat and Mass Transfer. 51. 1216-1225. DOI: http://dx.doi.org/10.1016/j.ijheatmasstransfer.2007.03.002

Revellin, R, Haberschill, P., Bonjour, J., Thome, J., 2008, Conditions of Liquid Film Dryout during Saturated Flow Boiling in Microchannels, Chemical Engineering Sciences, 63, 5795 - 5801.

DOI: http://dx.doi.org/10.1016/j.ces.2008.08.30

Revellin, R., Thome, J. R., 2009, Critical Heat Flux during Boiling in Microchannels: A Parametric Study, Heat Transfer Engineering, 30 (7), 556-563, DOI: http://dx.doi.org/10.1080/01457630802594879

Revellin, R., Mishima,K., Thome, J. R., 2009, Status of Prediction Methods for Critical Heat Fluxes in Mini and Microchannels, International Journal of Heat and Fluid Flow, 30, 983-992, DOI: http://dx.doi.org/10.1016/j.ijheatfluidflow.2009.04.006

Revellin, R., Thome, J., R., Bejan, A., Bonjour, J., 2009, Constructal Tree - Shaped Microchannel Networks for Maximizing the Saturated Critical Heat Flux, International Journal of Thermal Sciences, 48, 342 - 352. DOI: http://dx.doi.org/10.1016/j.ijthermalsci.2008.06.009

Roday, A.P., Jensen, M.K., 2007, Experimental Investigation of the CHF Condition During Flow Boiling of Water in Microtubes, in: ASME-JSME Thermal Engineering Summer Heat Transfer Conference, Vancouver, Canada.

Roday, A. P., Tasciuc, T.B., Jensen, M.K., 2008, The Critical Heat Flux Condition with Water in a Uniformly Heated Microtube, J. Heat Transfer, 130, 1-9, DOI: http://dx.doi.org/10.1115/1.2780181

Roday A. P., Jensen M. K., 2009, Study of Critical Heat Flux Condition with Water and R-123 during Flow Boiling in Microtubes. Part I: Experimental Results and Discussion of Parametric Effects, International Journal of Heat and Mass Transfer, 52, 3235-3249. DOI: http://dx.doi.org/10.1016/j.ijheatmasstransfer.2009.02.003

Roday A. P., Jensen M. K., 2009, Study of the Critical Heat Flux Condition With Water and R-123 during Flow Boiling in Microtubes. Part II - Comparison of Data with Correlations and Establishment of a New Subcooled CHF Correlation, International Journal of Heat and Mass Transfer, 52, 3250-3256, DOI: http://dx.doi.org/10.1016/j.ijheatmasstransfer.2009.02.004

Saitoh, S., Daiguji, H., Hihara, E., 2005, Effect of Tube Diameter on Boiling Heat Transfer of R134a in Horizontal Small Diameter Tubes, International Journal of Heat and Mass Transfer, 48, 4973-4984, DOI: http://dx.doi.org/10.1016/j.ijheatmasstransfer.2005.03.035

Shah, M. M., 1987, Improved general correlation for critical heat flux during upflow in uniformly heated vertical tubes, International Journal of Heat and Fluid Flow 8, 326-335. DOI: http://dx.doi.org/10.1016/0142-727X(87)90069-5

Son, G. and Dhir, V.K., 2008, "Numerical simulation of nucleate boiling on a horizontal surface at high heat fluxes," International Journal of Heat and Mass Transfer, 51(9-10), 2566-2582.

doi: http://dx.doi.org/10.1016/j.ijheatmasstransfer.2007.07.046

Sumith, B., Kaminaga, F., Matsumura, K., 2003, Saturated Flow Boiling of Water in a Vertical Small Diameter Tube, Exp. Therm. Fluid Sci., 27, 789-801. DOI: http://dx.doi.org/10.1016/S08941777(02)00317-5

Steinke, M.E., Kandlikar, S.G., 2004, An Experimental Investigation of Flow Boiling Characteristics of Water in Parallel Microchannels, $J$. Heat Transfer, 126, 518-526, DOI: http://dx.doi.org/10.1115/1.1778187

Stoddard R.M., Blasick A.M., Ghiaasiaan S.M., Abdel-Khalik S.I., Jeter S.M.,Dowling M.F., 2002, Onset of Flow Instability and Critical Heat Flux in Thin Horizontal Annuli, Experimental Thermal and Fluid 
Science, 26, 1-14, DOI: http://dx.doi.org/10.1016/S08941777(02)00110-3

Tomar, G., Biswas, G., Sharma, A. and Agrawal, A., 2005, Numerical simulation of bubble growth in film boiling using a coupled level-set and volume-of-fluid method, Physics of Fluids, 17(11), 112103. DOI:: http://dx.doi.org/10.1063/1.2136357

Thome, J. R., 2007, Engineering Data Book III, Wolverine Tube Inc.

Tong, L. S., 1968, Boundary-layer analysis of the flow boiling crisis, International Journal of Heat and Mass Transfer 11, 1208-1211. DOI: http://dx.doi.org/10.1016/0017-9310(68)90037-9

Vafaei, S., Wen, D., 2010, Critical Heat Flux of Subcooled Flow Boiling of Alumina Nanofluids in a Horizontal Microchannel, Journal of Heat Transfer, 132, 102404, 1-7, DOI: http://dx.doi.org/10.1115/1.4001629

Vandervort, C. L., Bergles, A. E., and Jensen, M. K., 1994, An Experimental Study of Critical Heat Flux in Very High Heat Flux Subcooled Boiling, International Journal of Heat and Mass Transfer, 37, suppl. 1, 161-173. DOI: http://dx.doi.org/10.1016/00179310(94)90019-1

Warrier, G.R., Dhir, V.K., Momoda, L.A., 2002, Heat Transfer and Pressure Drop in Narrow Rectangular Channels, Exp. Therm. Fluid Sci., 26, 53-64, DOI: http://dx.doi.org/10.1016/S0894-1777(02)00107-3

Wojtan, L., Revellin, R., Thome, J. R., 2006, Investigation of Saturated Critical Heat Flux in a Single, Uniformly Heated Microchannel, Experimental Thermal and Fluid Science 30. 765-774, DOI: http://dx.doi.org/10.1016/j.expthermflusci.2006.03.006
Wu, J.F. and Dhir, V.K., 2010, "Numerical Simulations of the Dynamics and Heat Transfer Associated With a Single Bubble in Subcooled Pool Boiling," Journal of Heat Transfer-Transactions of the ASME, 132(11). DOI: http://dx.doi.org/10.1115/1.4002093

Wu, Z., Li, W., Ye, S., 2011, Correlations for Saturated Critical Heat Flux in Microchannels, International Journal of Heat and Mass Transfer 54. 379-389, DOI: http://dx.doi.org/10.1016/j.jjheatmasstransfer.2010.09.033

Wu, Z., Li, W. 2011. A New Predictive Tool for Saturated Critical Heat Flux in Micro/Mini-Channels: Effect of the Heated Length-to-Diameter Ratio, International Journal of Heat and Mass Transfer, 54, 2880 2889,

DOI: http://dx.doi.org/10.1016/j.ijheatmasstransfer.2011.03.011

Yu, W., France, D. M., Wambsganss, M. W., Hull, J. R., 2002, TwoPhase Pressure Drop, Boiling Heat Transfer, and Critical Heat Flux to Water in a Small-Diameter Horizontal Tube, International Journal of Multiphase Flow 28. 927-941, DOI: http://dx.doi.org/10.1016/S03019322(02)00019-8

Zuber, N., 1959, Hydrodynamic Aspects of Boiling Heat transfer, Ph.D. thesis, Research Laboratory, Los Angeles and Ramo-Wooldridge Corporation, University of California, Los Angeles, CA

Zhang, W., Hibiki, T., Mishima, K., Mi, Y., 2006, Correlation of Critical Heat Flux for Flow Boiling of Water in Mini-Channels. International Journal of Heat and Mass Transfer, 49, 1058-1072, DOI: http://dx.doi.org/10.1016/j.ijheatmasstransfer.2005.09.004 